Article

\title{
Topology of a Bidirectional Converter for Energy Interaction between Electric Vehicles and the Grid
}

\author{
Jiuchun Jiang ${ }^{1, *}$, Yan Bao ${ }^{1,2, *}$ and Le Yi Wang ${ }^{2}$ \\ 1 School of Electrical Engineering, Beijing Jiaotong University, Beijing 100044, China \\ 2 Department of Electrical and Computer Engineering, Wayne State University, Detroit, MI 48202, \\ USA; E-Mail: lywang@wayne.edu
}

* Authors to whom correspondence should be addressed; E-Mails: jcjiang@bjtu.edu.cn (J.J.); baoyan4u@gmail.com (Y.B.); Tel./Fax: +86-10-5168-3907 (J.J. \& Y.B.).

Received: 16 April 2014; in revised form: 18 July 2014 / Accepted: 21 July 2014 /

Published: 30 July 2014

\begin{abstract}
In vehicle-to-grid (V2G) systems, electric vehicles interact with the grid as distributed energy storage systems that offer many potential benefits. As an energy interface between a vehicle and the grid, the bidirectional converter plays a crucial role in their interaction. Its reliability, safety, cost, efficiency, weight, size, harmonics, and other factors are of essential importance for $\mathrm{V} 2 \mathrm{G}$ realization, especially for on-board operations. Beyond the common existing topologies for bidirectional chargers, this paper introduces a novel high-power-factor bidirectional single-stage full-bridge (BSS-FBC) topology, which offers advantages in power density, size, weight, cost, efficiency, power quality, dynamic characteristic, reliability, and complexity. Its operational principles and control strategies are presented. Harmonic analysis on the basis of double-Fourier integral is performed with detailed comparison of line current harmonic characteristics between the BSS-FBC topology and unipolar/bipolar controlled single-phase pulse width modulation (PWM) converters. A dynamic model of the topology is derived, its dynamic behavior analyzed, and its compensator design method developed. Simulation and experimental results are employed to verify the design and analysis. Design considerations for the key parameters are discussed. A $3.3 \mathrm{~kW}$ prototype is developed for this topology and validated in its vehicle applications. The results demonstrate clearly the benefits and advantages of the new topology.
\end{abstract}

Keywords: vehicle-to-grid; bidirectional converter; single-stage; harmonic analysis; dynamic characteristic 


\section{Introduction}

With natural resources depleting at an alarming pace and the increase of pollution, the Smart Grid has been recognized as a promising technology advancement to address these issues [1,2]. For the same reason, electric vehicles (EV) with their zero emission characteristics have become a main driving force in the automotive industry as the greener vehicles of the next generation $[3,4]$. While integration of large quantities of electric vehicles into the grid brings new technical and infrastructure challenges for sustained load growth and management, it also presents new opportunities in providing flexibility in power management in distribution networks $[5,6]$. In particular, beyond their typical roles as loads to a power system, electric vehicle battery systems can serve as distributed energy storage for grid power management. Managed properly, they can potentially improve the reliability and stability of utility grids, support integration of renewable energy generations, and improve overall system efficiency, leading to the concept of vehicle-to-grid (V2G) [7-12].

In recent years, there has been growing interest in $\mathrm{V} 2 \mathrm{G}$. The research on its impact on power systems has intensified recently since more and more scholars have focused on the V2G technologies. Among them, control strategies for different control objectives are the most studied topics. In [13] the authors aimed to minimizing load variance in household microgirds. In [14,15], a two-stage optimization model is adopted to minimize the peak load and load fluctuation. V2G control strategies aiming at peak shaving and valley filling are presented in [16-19], with costs of all energy resources and system operation as the minimization objective. In [20-22] control strategies based on aggregators' cost or EV owners' cost are introduced. Generally, most of the above methods are optimization problems with explicit objective functions, and can be solved by quadratic programming, mixed-integer programming, particle swarm optimization, or other methods. Recently, real-time V2G control has emerged as a promising future research direction [23-26]. Also, real-time control strategies for EVs in participation of frequency regulation are still actively pursued [27-30]. Furthermore, substantial research efforts have been dedicated to battery management in V2G applications, such as battery models and state estimation [31,32]. V2G-related communication and network solutions are another actively studied V2G technical topic area, especially in terms of standards, network architecture, privacy preservation, and security protection [33-35].

Within the smart grid framework adopted by the U.S. National Institute of Standards and Technology (NIST), V2G aims to achieve two fundamental functions: information interaction and energy interaction [36]. Beyond the above V2G technologies, as an energy interface, bidirectional converters are the foundation for electric vehicles to realize their roles as mobile energy storage systems. Consequently, their reliability, safety, cost, efficiency, weight, size, harmonics, and many other factors have a critical impact on the energy interaction.

Bidirectional converter topologies have been studied extensively as electric vehicles chargers. They can be divided into two basic classes: off-board bidirectional chargers and on-board bidirectional chargers [37]. Off-board bidirectional chargers commonly employ two-stage topologies that combine a three-phase pulse width modulation (PWM) converter and a bidirectional DC-DC converter. Their components typically are of large power rating and size, and they are often used in rapid charging and discharging applications [37-39]. Due to their power rating, size, cost, and noise, off-board bidirectional chargers are more suitable for commercial charging stations, rather than residential areas. 
On-board bidirectional chargers are designed for residential usage and slow charging, whose low power levels, about 1.4-1.9 $\mathrm{kW}$ in North America and $3 \mathrm{~kW}$ in China (Table 1), are desirable due to their low infrastructure investment and convenient charging conditions. On-board bidirectional chargers can be further divided into two main types of structures: reused (or integrated) structures and independent structures. In the reused structure, the EV motor's inverter is used as the full-bridge circuit of the grid-tied inverter; the EV motor's windings as the input inductances of the grid-tied inverter; and the EV motor itself as a line-frequency transformer for galvanic isolation [40-48]. By using the existing system in the EV, the reused topologies incur lower costs. However, these topologies introduce significantly complications in converter design and control of the on-board system. For this reason, this paper mainly focuses on independent on-board bidirectional topologies.

Table 1. North America and China charging levels for electric vehicles.

\begin{tabular}{cccc}
\hline Region & Charging Method & Nominal Supply Voltage & Maximum Current \\
\hline \multirow{4}{*}{ North } & AC Level 1 & Single phase 120 V AC & $12 \mathrm{~A}$ \\
America & AC Level 2 & Single phase 120 V AC & $16 \mathrm{~A}$ \\
& DC Level 1 & $200-500 \mathrm{~V}$ DC & $\leq 80 \mathrm{~A}$ \\
& DC Level 2 & $200-500 \mathrm{~V} \mathrm{DC}$ & $\leq 80 \mathrm{~A}$ \\
& 1 & & \\
& 2 & Single phase 220 V AC & $16 \mathrm{~A}$ \\
\hline \multirow{2}{*}{ China } & 3 & & $32 \mathrm{~A}$ \\
& 4 & $400 \mathrm{~V} / 750 \mathrm{~V} \mathrm{DC}$ & $125 \mathrm{~A}$ \\
& & & $250 \mathrm{~A}$ \\
\hline
\end{tabular}

Before introducing our new topology, in Section 2 we first summarize the main characteristics and principles of several typical topologies that have been applied to electric vehicle bidirectional chargers. Shortcomings of these topologies will be highlighted in terms of power density, component count, size, weight, cost, efficiency, and complexity, which are the major design challenges for on-board or external small-power bidirectional chargers. Furthermore, harmonic characteristics of the converters are especially important since high-order harmonics from converters can have detrimental effects on the grid stability. Finally, fast response of bidirectional chargers is pivotal in realizing V2G frequency regulation.

Addressing these challenges, a novel high power factor bidirectional single-stage full-bridge (BSS-FBC) topology is proposed for the first time in this paper. The main contributions of this paper are: (1) introduction of the new BSS-FBC topology; (2) comprehensive analysis of its functions, features, and benefits; (3) prototype development of this technology; and (4) verification of the design and its benefits in a vehicle application.

Compared to the existing two-stage topologies detailed in Section 2, under the same unity power factor operating ability, high frequency galvanic isolation, and bidirectional energy conversion, this converter offers the following distinct advantages:

(1) It eliminates the bulky and expensive DC intermediate link capacitors and the inductor in the bidirectional DC-DC stage of two-stage topologies, resulting in reduced component counts, smaller size, lighter weight, and higher power density. 
(2) By removing the expensive DC link capacitors and special customized DC-DC inductor in the typical two-stage topologies, the cost of passive components is reduced significantly. Furthermore, in contrast to two-stage topologies, four AC-side switches in our converter work under low frequency and low voltage stress, leading to less expensive component selection and lower cost on active components.

(3) For the same inductance and switching frequency, this topology has less harmonic components than unipolar/bipolar modulated single-phase PWM converters that act as the first stage of the two-stage converters.

(4) With the same ripple factor and switching frequency, inductance $L$ of this topology is much smaller, leading to improved dynamic response after applying suitable feedback control systems.

(5) Due to lower losses on passive components, lower conduction losses on low voltage stress switches, and four zero-switching-loss active switches, this topology is of much higher energy efficiency (soft-switching of the bidirectional DC-DC stage in the two-stage topologies cannot be guaranteed, especially when loads vary in a wide range or power flow varies).

(6) Elimination of electrolytic capacitors in the DC intermediate link, and one-stage control system (which can be implemented by one micro control unit, in contrast to the typical topologies in which two controllers are needed) enhance converter reliability and reduce complexity.

The remainder part of the paper is organized into the following sections: after a review of the existing topologies in Section 2, firstly the operational principles and steady-state characteristics of our topology are described in Section 3. Then, the PWM modulation mode of this topology is presented and harmonic analysis on the basis of double-Fourier integral methods is performed with detailed comparison of line current harmonic characteristics between the BSS-FBC topology, unipolar/bipolar controlled single-phase PWM converters. Based on a dynamic model of the topology, design procedures for the compensator are presented and dynamic response characteristics of this topology are analyzed. Simulation results and experimental systems are employed to verify the design and analysis. Design considerations for the key parameters are discussed in Section 4. Section 5 discusses the main advantages and unique features of this topology. A $3.3 \mathrm{~kW}$ prototype system is developed for this topology in Section 6, and validated in its vehicle applications. The results demonstrate clearly the benefits and advantages of the new topology. Finally, Section 7 concludes this paper with some remarks on potential future directions.

\section{Typical Topologies of Bidirectional Converters for Connecting Electric Vehicles and Grid}

As the interface between an electric vehicle and a utility grid, the bidirectional converter must accommodate certain essential requirements from both the vehicle and grid. Passenger electric vehicles commonly have a maximum battery voltage between 300 and $400 \mathrm{~V}$, and a bidirectional charger power rating of around $3 \mathrm{~kW}$ in the on-board charging mode. In consideration of isolation, voltage stress, and current stress, full-bridge topologies are usually preferred. Moreover, on-board conditions require the converter to have high power density, small size, light weight, cost-effective, safe, and reliable. For utility grids, bidirectional chargers must meet relevant harmonic standards (e.g., IEEE1547 [49], IEC61000 [50], etc.). Furthermore, high energy conversion efficiency is required. 
Bidirectional chargers can be divided into isolated and non-isolated types. Figure 1 depicts a topology that can be used for non-isolated on-board bidirectional chargers [51-54]. It is composed of single-phase PWM converter and bidirectional buck-boost DC-DC converter. This topology uses fewer switches. However, without galvanic isolation, safety of its operation is compromised.

Figure 1. Topology of non-isolated on-board bidirectional charger composed of pulse width modulation (PWM) converter and bidirectional buck-boost DC-DC converter.

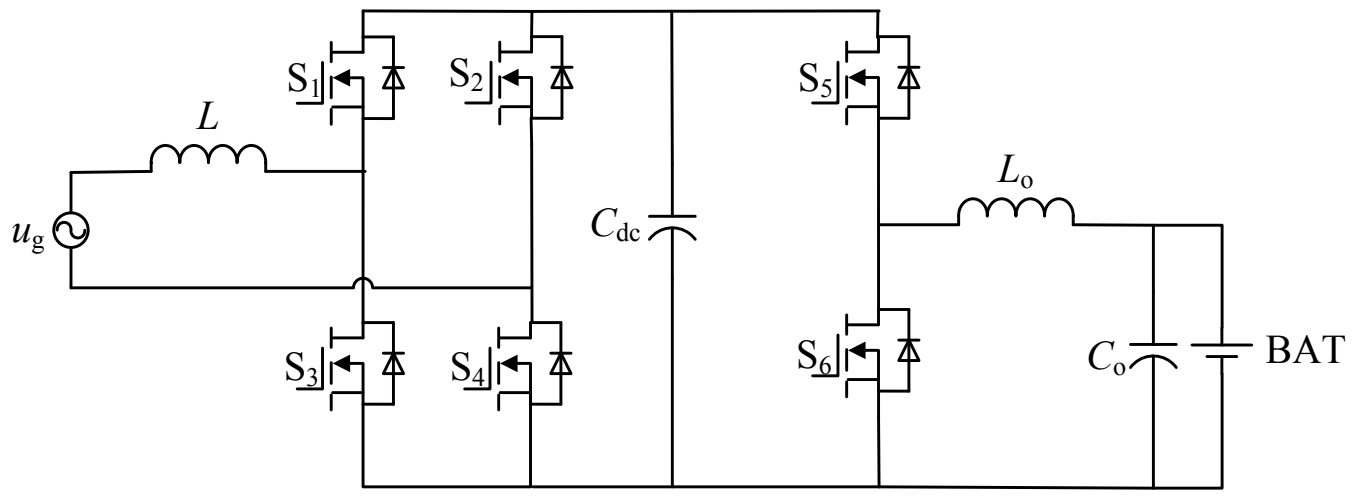

Figure 2 depicts a topology composed of single-phase PWM converter and cascaded buck-boost DC-DC converter [55]. The cascaded buck-boost converter allows bidirectional energy flow and overlapping input and output voltage ranges. Actually, the intermediate capacitor bank has already changed the cascaded buck-boost converter into two stages each one of which can act either as a buck converter or a boost converter. This will leads to better applicability to battery voltage, but higher power losses compared to the topology shown in Figure 1.

Figure 2. Topology of non-isolated on-board bidirectional charger composed of PWM converter and cascaded buck-boost DC-DC converter.

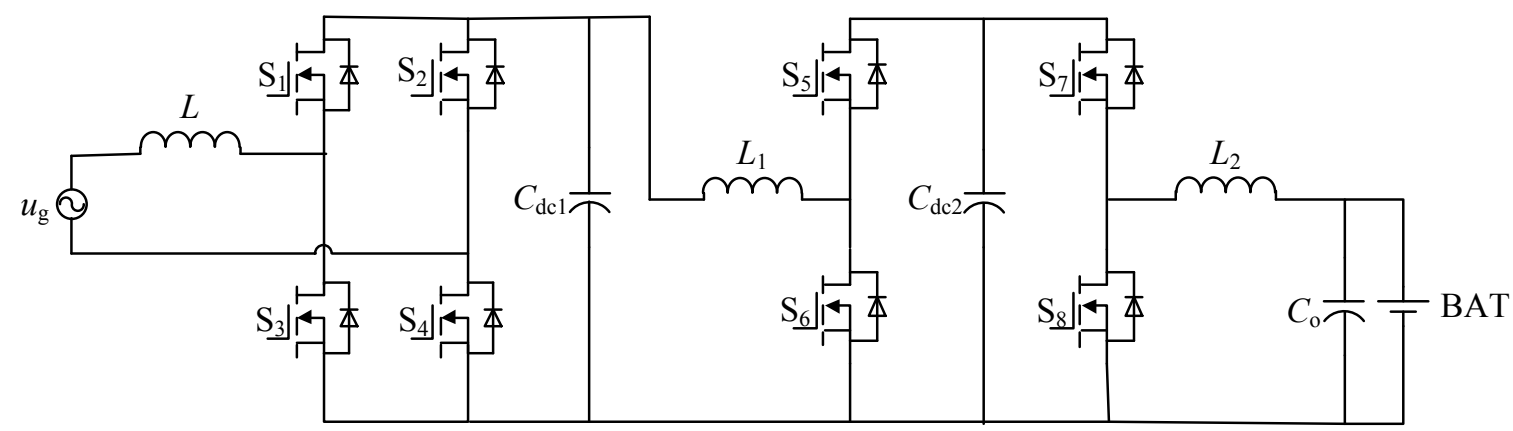

Figure 3 depicts an integrated bidirectional charger composed of eight-switch inverter (ESI) and interleave DC-DC converter, integrating the DC/DC converter, on-board bidirectional charger, and DC-AC inverter together [56,57]. The first stage of this topology can act as three-phase DC-AC inverter or single-phase PWM converter to realize traction/regenerative and charging/discharging respectively, without any relays or other switching devices to change the operating modes compared to most other integrated topologies. Accordingly, this bidirectional multi-function two-stage topology implements a complex controller and introduces significantly complications in converter design. In addition, it is still a non-isolated topology. 
Figure 3. Topology of non-isolated integrated bidirectional charger composed of eight-switch inverter (ESI) and interleave DC-DC converter.

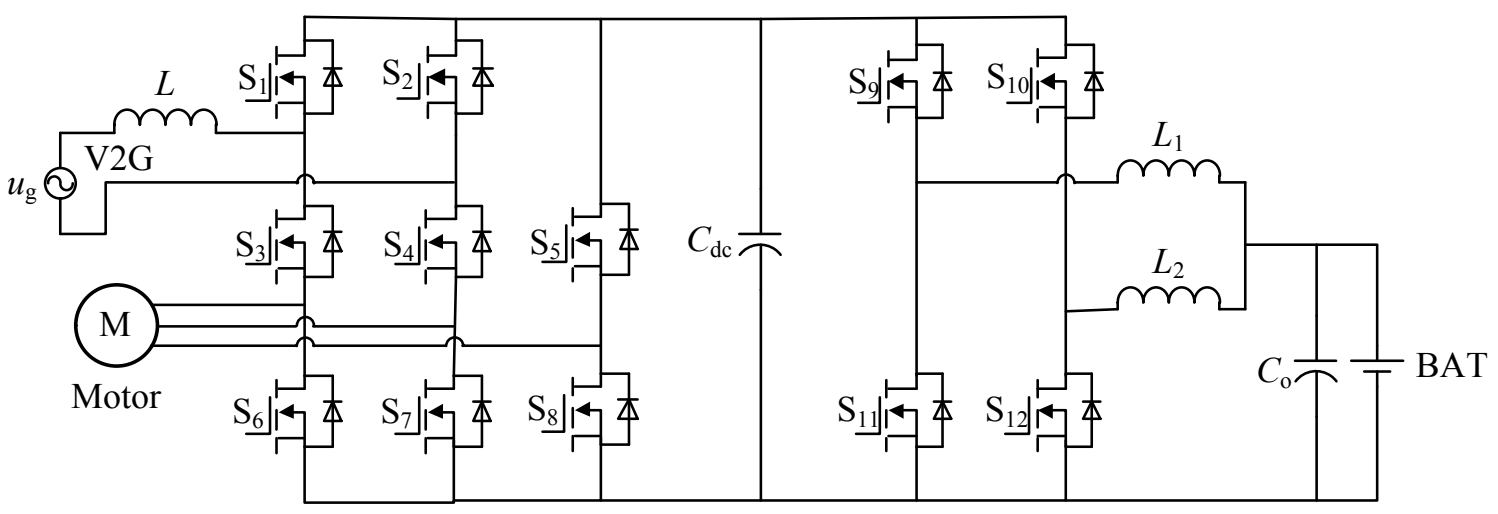

Transformers are used in most applications that require voltage matching and/or galvanic isolation between the utility grid and the energy storage device [37]. If the topology shown in Figure 1 is expanded with line-frequency isolation, its volume, weight, and noise will increase significantly. Consequently, in the on-board condition, several topologies that replace the line-frequency transformer by a high-frequency isolation transformer are commonly used which make the mobile energy storage system more compact and flexible. Figure 4 is a two-stage topology that consists of a single-phase PWM AC-DC converter and a dual-active-bridge (DAB) high-frequency isolated DC-DC converter [58-62]. This topology improves safety and reduces size of the converter. The DC-DC part of this topology is controlled by a phase shift control to achieve zero-voltage switching (ZVS) turning-on of $\mathrm{S}_{5}-\mathrm{S}_{12}$. The lead and lag relationship between the two bridges (i.e., the polarity of the phase shift angle) determines the direction of energy flow; and the phase shift angle controls the output power. Like most voltage-fed topologies, DAB converters suffer from several limitations, including high input pulsating current, limited soft-switching range, high circulating current through devices and magnetics, etc. [63].

Figure 4. A two-stage topology composed of PWM converter and dual-active-bridge (DAB).

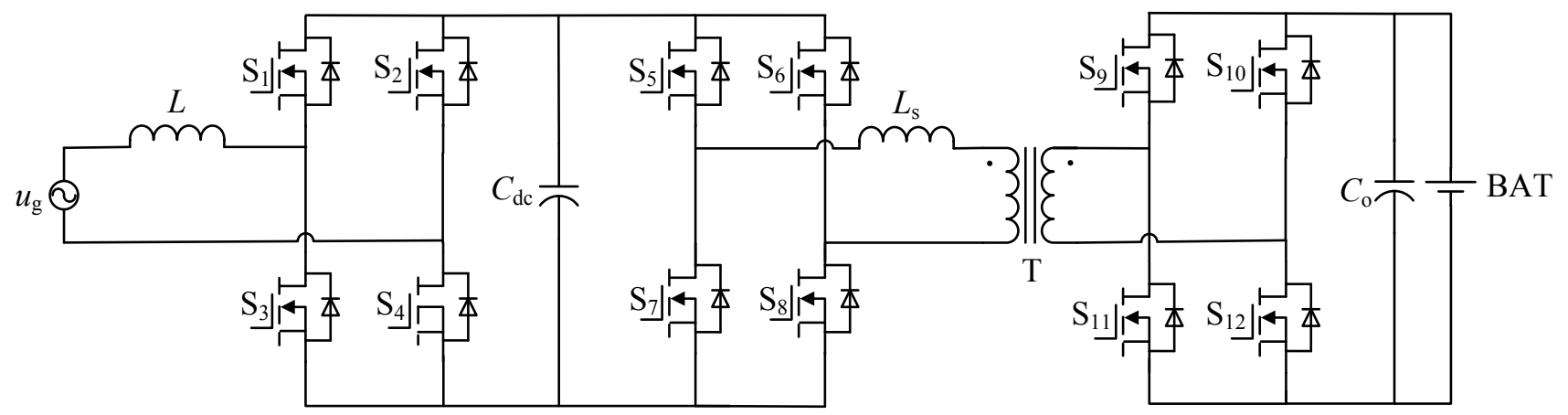

Similar to the topology in Figure 4, Figure 5 is a topology with a single-phase PWM converter in its AC-DC stage and a series resonant converter (SRC) in its high-frequency isolated DC-DC stage [64,65], The phase shift control is also used to achieve the ZVS turning-on of the four switches in the primary and the zero-current switching (ZCS) turning-off of the four switches in the secondary, as well as the bidirectional energy flow. Compared with the non-resonant DAB converter, the peak current of SRC is much higher which increases current stress of the switches and magnetics, and requires higher rating of 
components [63]. The resonant capacitor also increases its size and weight. Therefore, it is not a preferred topology for this application.

For V2G applications, contactless topologies have been proposed that use wireless energy transmission through loosely coupled transformers by resonant. These topologies offer more flexibility and convenience in charging/discharging operations. Figure 6 depicts a two-stage contactless topology that is composed of a single-phase PWM converter, an inductive power transfer (IPT) high-frequency isolated DC-DC converter [66]. LCL parallel resonant circuits are used to achieve ZVS turning-on of the eight switches in the DC-DC part of this topology. The output power is controlled by the angle difference between the secondary and primary voltages of the transformer. However, the transmission efficiency of the DC-DC part in this topology is low, typically about $85 \%$, and hence does not satisfy efficiency standards of $\mathrm{V} 2 \mathrm{G}$ applications.

Figure 5. A two-stage topology composed of PWM converter and series resonant converter (SRC).

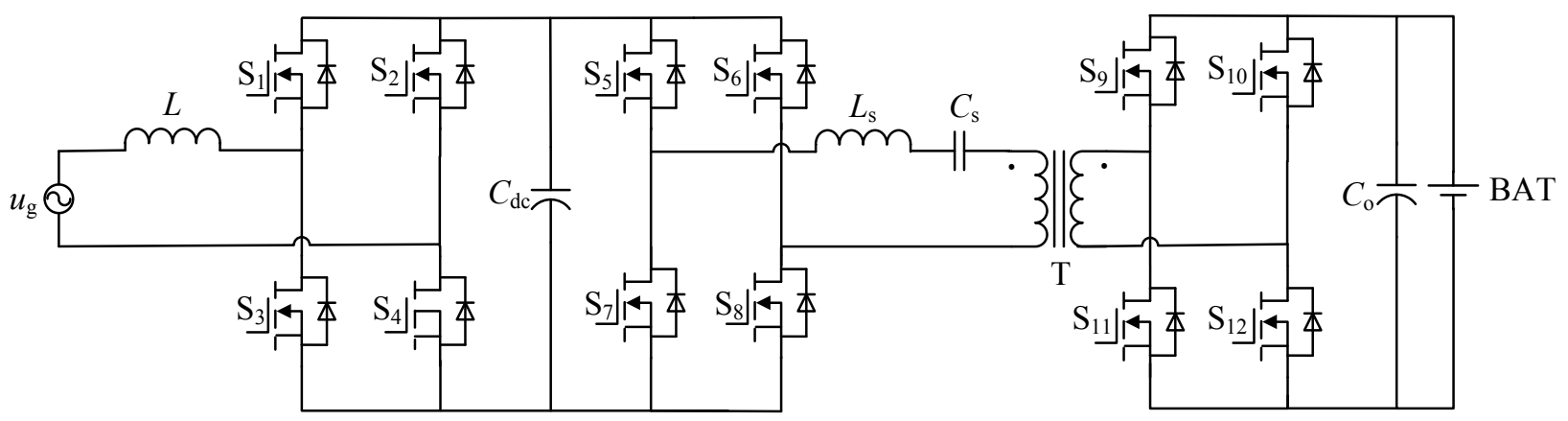

Figure 6. A two-stage topology composed of PWM converter and inductive power transfer (IPT).

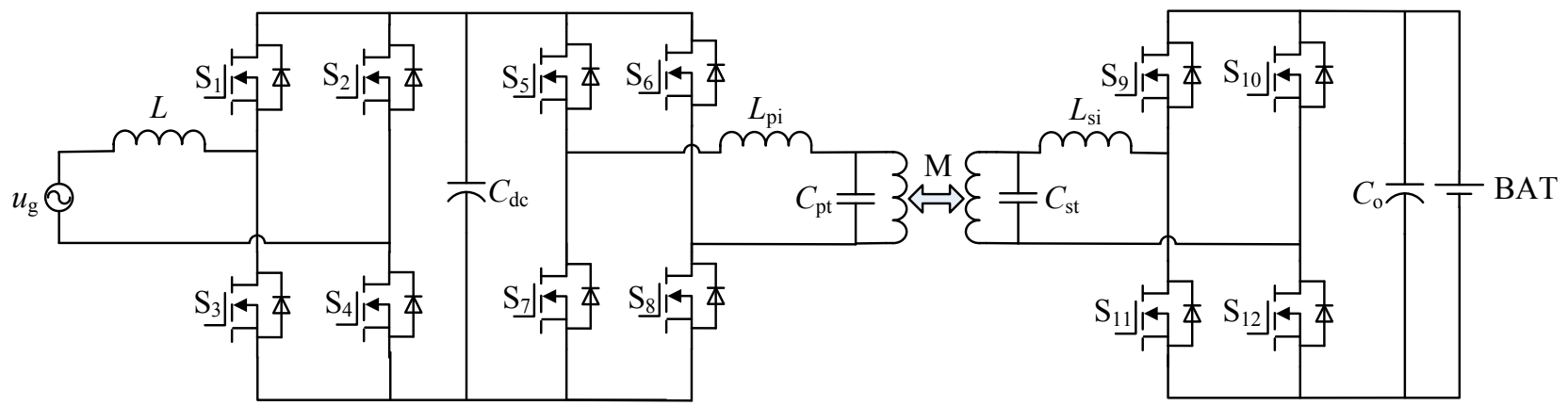

Based on the inductive power transfer topology in Figure 6, a matrix converter based bidirectional IPT topology has been developed for $\mathrm{V} 2 \mathrm{G}$ applications, shown in Figure 7 , in which $\mathrm{S}_{1}-\mathrm{S}_{4}$ are bidirectional switches [67]. The topology uses a single-stage power conversion, eliminating the DC link to improve system efficiency. Since this topology uses only one DC capacitor, it has the apparent advantage of small size and low cost. However, the grid-side current waveforms of this topology contain high harmonic contents.

Figure 8 is a bidirectional single-stage topology based on an AC-DC DAB converter [68-70]. The primary side of this topology is a single-phase matrix converter, in which $\mathrm{S}_{1}-\mathrm{S}_{4}$ are bidirectional switches. Each of the bidirectional switches is composed of two reverse tied active switches. This topology can naturally allow bidirectional energy flow using the principle of bidirectional power flow in DAB converter (by a phase shift control). Due to grid-side current distortion created by converter 
operation, the input filter is necessary, and need to be well designed to comply with the power quality standards. Furthermore, its control scheme and switching commutation strategy increase the complexity of this topology. In addition, its secondary side peak current is high result in a higher power rating switches selected.

Figure 7. A bidirectional IPT single-stage topology based on matrix converter.

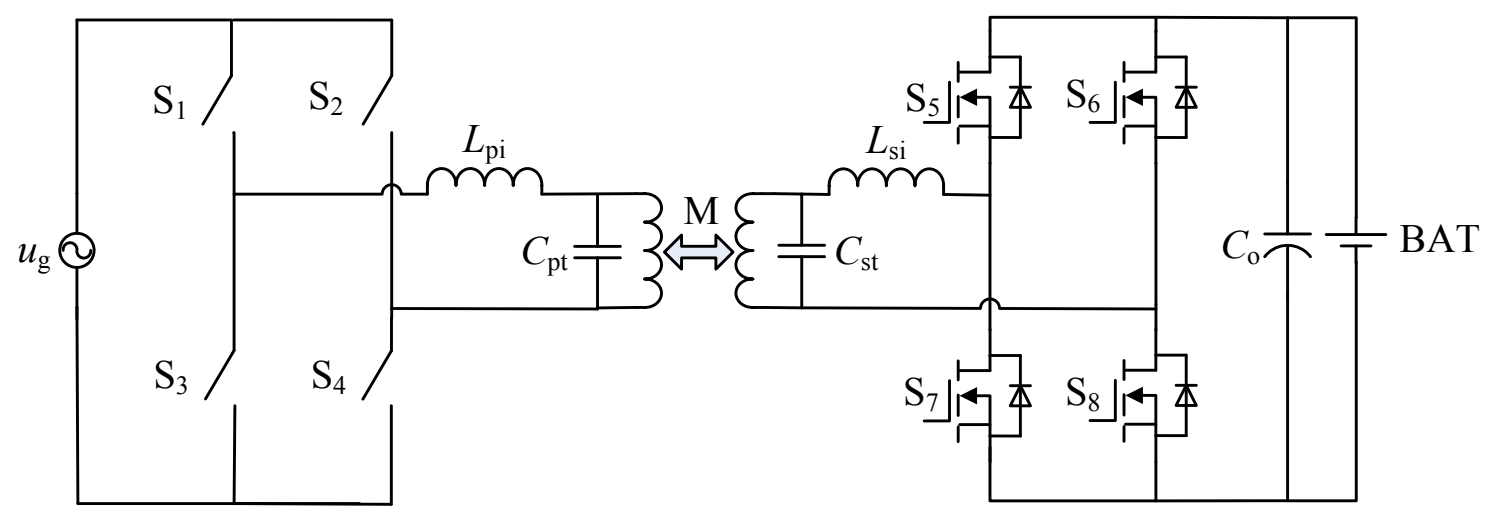

Figure 8. A bidirectional single-stage topology based on AC-DC dual-active-bridge (DAB).

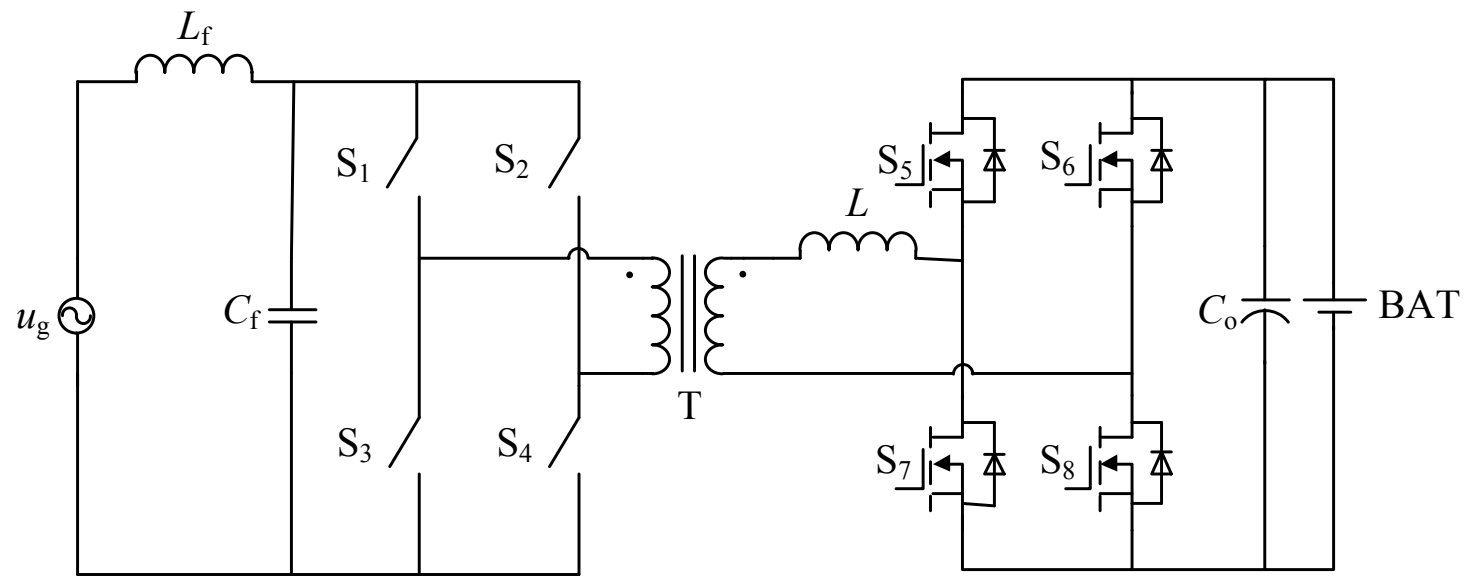

\section{Novel High Power Factor Bidirectional Single-Stage Full-Bridge Topology}

The main goal of this paper is to develop a new topology of bidirectional on-board converters to address the key issues elaborated in Section 2, and to achieve high power density, small size, low weight, reduced cost, improved efficiency, low harmonic distortion, and enhanced reliability. Common bidirectional converters with preferable harmonic indices adopt a two-stage structure with a grid-side current shaping stage (PWM converter) and a bidirectional DC-DC converter stage (Figures 1-6). They suffer from low power density and efficiency, as well as high cost. The relatively short life of DC link electrolytic capacitors reduces system reliability [39,67]. Usually these two stages are controlled separately by two micro control units using different control strategies, leading to high complexity.

To overcome these shortcomings, a novel bidirectional topology for energy interaction between electric vehicles and grids is proposed in this paper. The main idea is to integrate the grid-side current shaping stage and DC-DC conversion stage into a single-stage structure. The topology and its analysis are detailed next. 


\subsection{Topology of the Novel Converter}

Figure 9 shows the proposed topology of a high power factor bidirectional single-stage full-bridge converter. $L$ is the filtering inductor; $C_{\mathrm{o}}$ is the energy storage capacitor; $T$ is a high-frequency isolation transformer; and BAT is the battery pack. $C_{1}$ is the dead-time capacitor whose capacitance is quite small and mainly works as the snubber capacitor during dead time in the discharging mode to absorb the remaining small inductor current, and as such a diminutive film capacitor can be used. This topology eliminates the bulky and expensive DC intermediate link capacitors and the resonant tank in the common two-state topologies, and employs a single-stage conversion to achieve unity power factor operation. Compared to the foregoing typical topologies, this topology contains only one inductor and one storage capacitor, has higher power density, smaller size, lighter weight, reduced cost, and improved reliability. Also losses on the passive components are reduced, making it suitable for applications to the on-board environment. Moreover, its line-frequency switching bridge $\left(\mathrm{S}_{1}-\mathrm{S}_{4}\right)$ has no switching loss, leading to higher energy efficiency. In addition, unlike the typical two-stage topologies in which twelve switches operate in high frequency and under high voltage stress, the lower switching frequency and voltage stress of $\mathrm{S}_{1}-\mathrm{S}_{4}$ in this topology implies that active components of lower grade can be selected, and conduction losses and costs are lower. Finally, $\mathrm{S}_{1}-\mathrm{S}_{4}$ don't need to be controlled and can be driven by pulses with fixed duty cycles, further simplifying the control complexity.

Figure 9. Topology of novel bidirectional single-stage full-bridge (BSS-FBC).
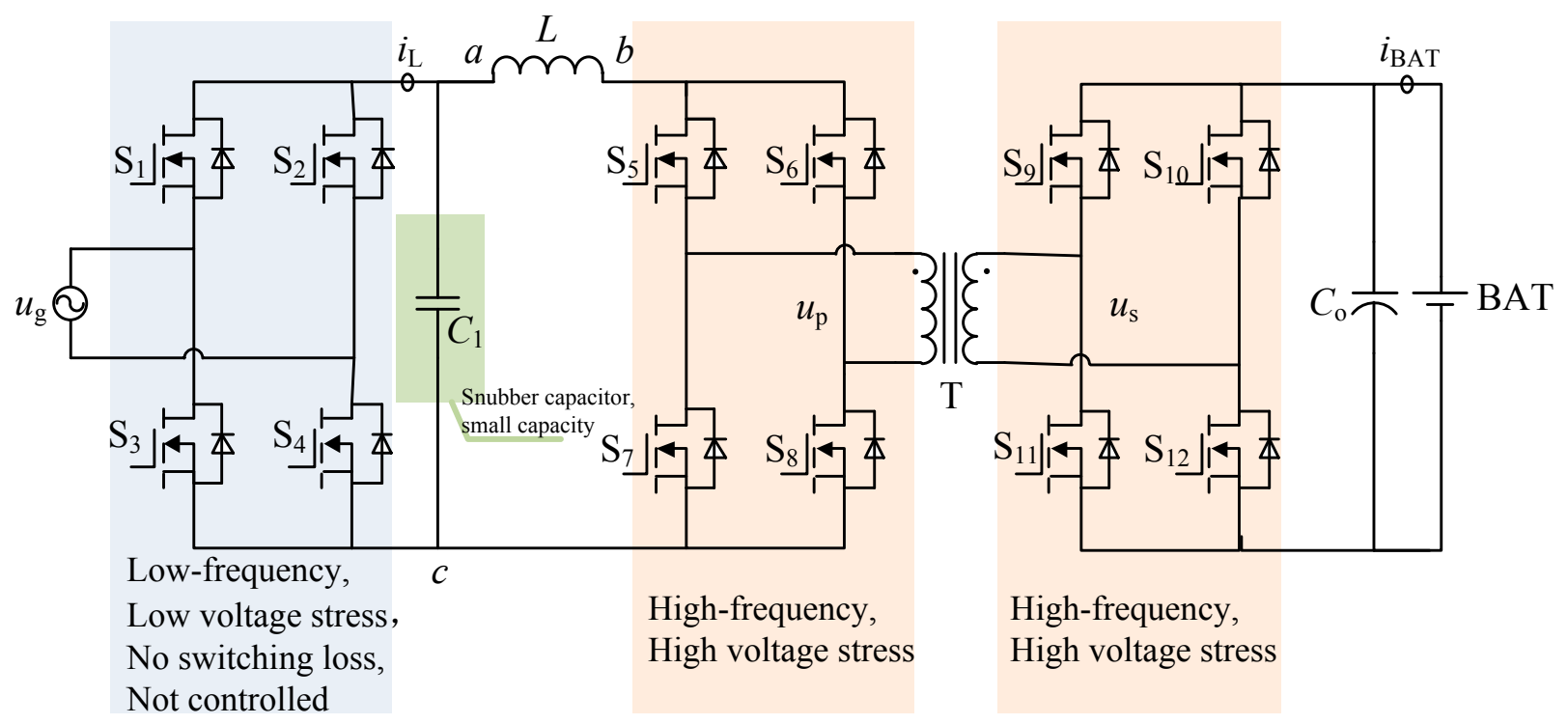

\subsection{Operational Principles}

In order to derive the operational characteristics of the new topology, it is assumed that all the switches are ideal. And to simplify the analysis, it is also assumed that the leakage inductance of the high-frequency transformer $T$ is zero in the ideal condition. The energy storage capacitor $C_{\mathrm{o}}$ is sufficiently large and the voltage of the battery pack BAT is a constant in an operational cycle. The operational process is divided into the charging mode and discharging mode, and their operational principles are analyzed next. Figure 10 depicts different operation modes of BSS-FBC in charging and discharging mode. 
Figure 10. Different operation modes of novel BSS-FBC.
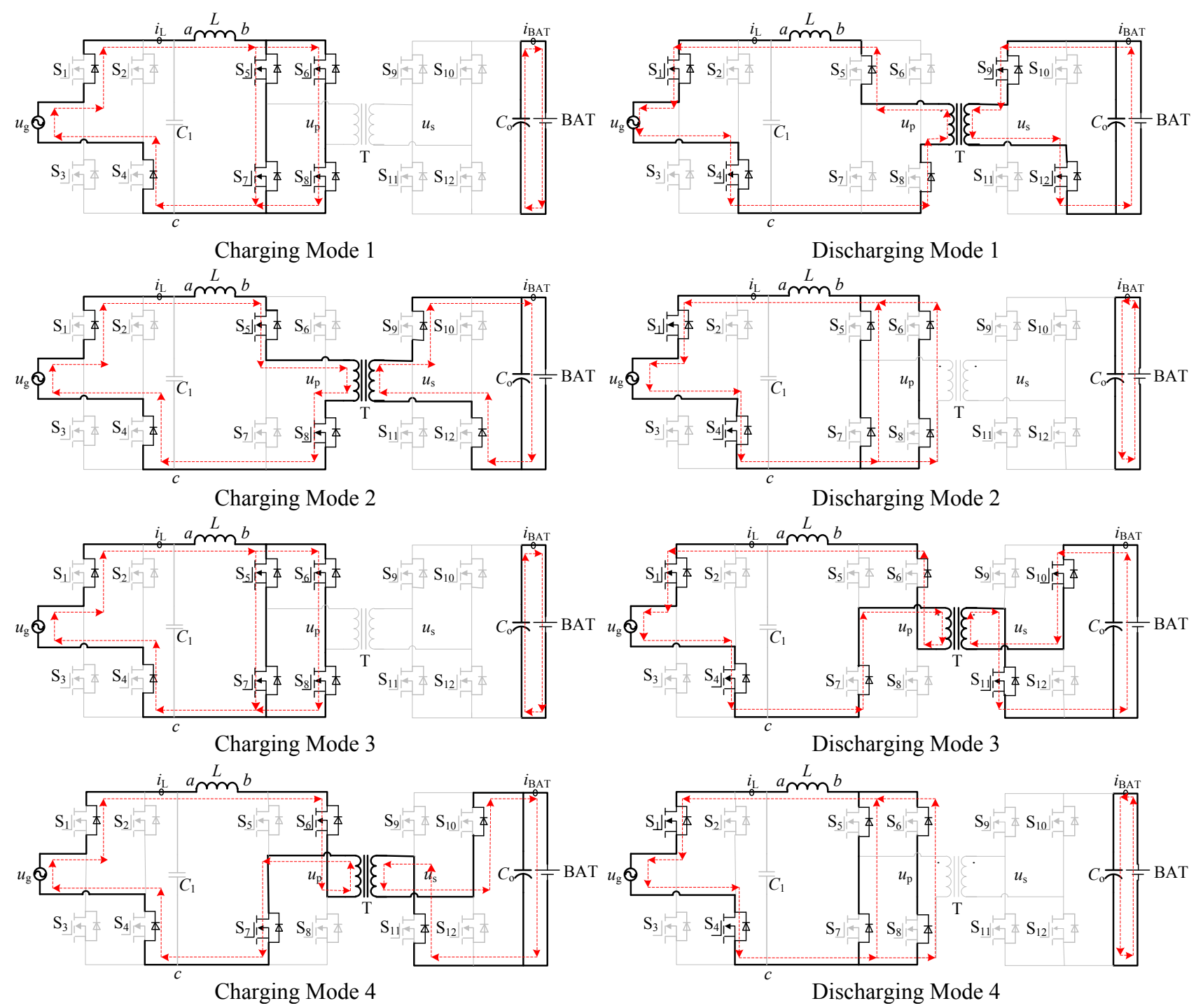

\subsubsection{Charging Mode}

In the charging mode, $\mathrm{S}_{1}-\mathrm{S}_{4}$ and $\mathrm{S}_{9}-\mathrm{S}_{12}$ are without driving pulse and work in the diode rectification state, while $\mathrm{S}_{5}-\mathrm{S}_{8}$ work alternately in accordance with the high-frequency pulses shown in Figure 11. From top to bottom in Figure 11 are the waveforms of $S_{5}$ and $S_{8}$ 's driving pulses, $S_{6}$ and $\mathrm{S}_{7}$ 's driving pulses, the inductor current, and the primary voltage of the transformer.

As shown in Figures 10 and 11, BSS-FBC operates in accordance with the order of mode 1-mode 2-mode 3-mode 4 circularly in charging mode. When $\mathrm{S}_{5}-\mathrm{S}_{8}$ are all turned on (charging mode 1 or 3 in Figure 10), the current of the inductor $L$ increases linearly, and the inductor absorbs energy. When $\mathrm{S}_{5}$, $\mathrm{S}_{8}$ or $\mathrm{S}_{6}, \mathrm{~S}_{7}$ are turned on (charging mode 2 or 4 in Figure 10), the inductor $L$ releases energy, its current decreases linearly, and transfers energy to the battery through the transformer. Considering the leakage inductance of the transformer, it has to add a passive snubber $\left(R_{C}, C_{C}, D_{C}\right)$ at point a, b, and c in Figure 9 to avoid the damage caused by voltage spike. In the charging mode, this topology is equivalent to boost power factor correction (PFC). It operates in continuous current mode, and the dead-time capacitor $C_{1}$ works as the input capacitor of the PFC converter with the Electromagnetic 
Interference (EMI) filtering effect [71]. The relationship between the input and output can be expressed as:

$$
U_{\mathrm{O}}=\frac{1}{N(1-D)} U_{\mathrm{I}}
$$

where $U_{\mathrm{O}}$ is the output voltage of the battery side, $U_{\mathrm{I}}$ is the rectified input voltage, $N$ is the transformer turn ratio, and $D$ is the duty cycle.

Figure 11. Operational principle of BSS-FBC in charging mode.

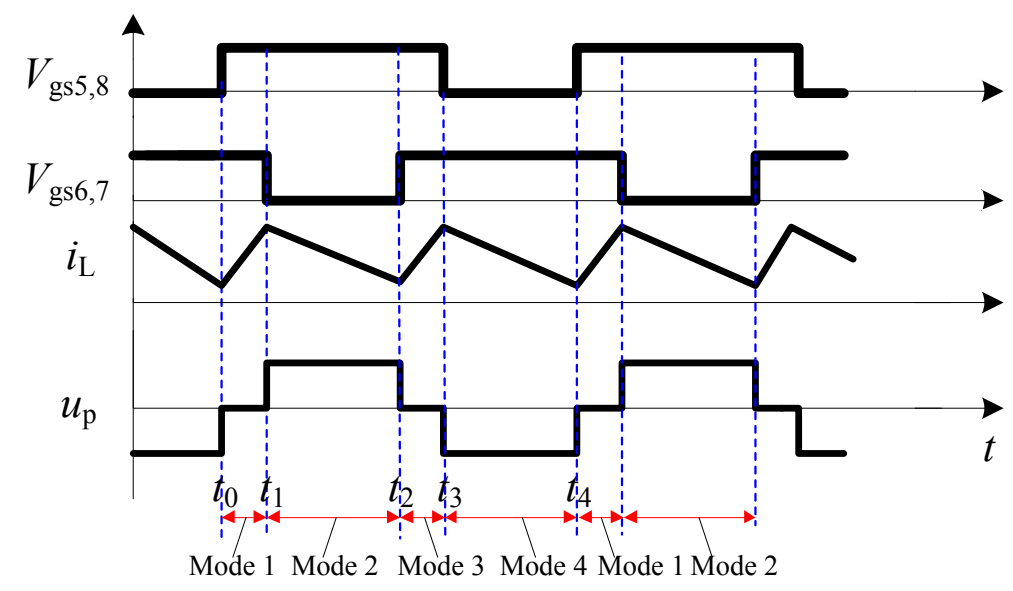

\subsubsection{Discharging Mode}

In the discharging mode, $\mathrm{S}_{5}-\mathrm{S}_{8}$ are not driven by the pulse but rather work in the diode rectification state, while $\mathrm{S}_{9}-\mathrm{S}_{12}$ work alternately in accordance with the high-frequency pulses shown in Figure 12a, and $S_{1}-S_{4}$ work alternately in accordance with the grid voltage as shown in Figure $12 \mathrm{~b}$. Because $S_{1}-S_{4}$ switch at the zero-crossing point of the grid voltage and current, there are no switching losses, but only conduction losses. From top to bottom in Figure 12a are the waveforms of $\mathrm{S}_{9}$ and $\mathrm{S}_{12}$ 's driving pulses, $\mathrm{S}_{10}$ and $\mathrm{S}_{11}$ 's driving pulses, the inductor current, and the secondary voltage of the transformer. Figure $12 \mathrm{~b}$ shows the line-frequency waveforms of this topology: (top to bottom) the waveforms of the inductor current, the driving pulses of $S_{1}$ and $S_{4}$, the driving pulses of $S_{2}$ and $S_{3}$, and the grid current.

Figure 12. Operational principle of BSS-FBC in discharging mode: (a) High-frequency waveforms of this novel topology; (b) Line-frequency waveforms of this novel topology.

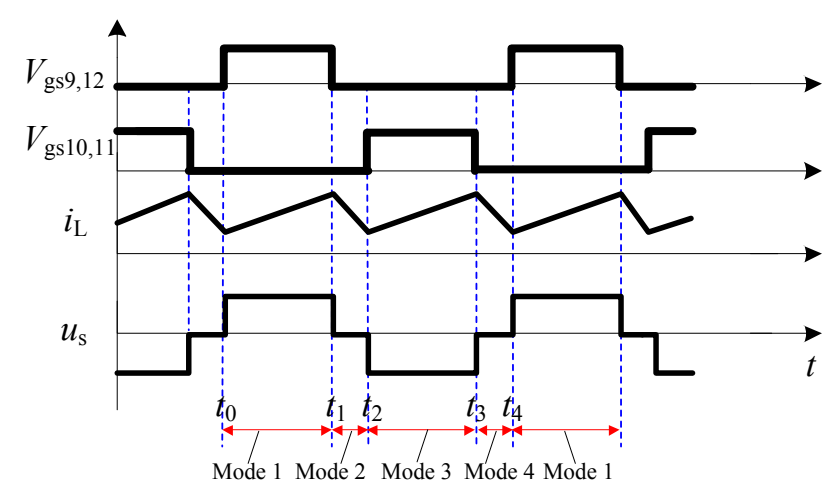

(a)

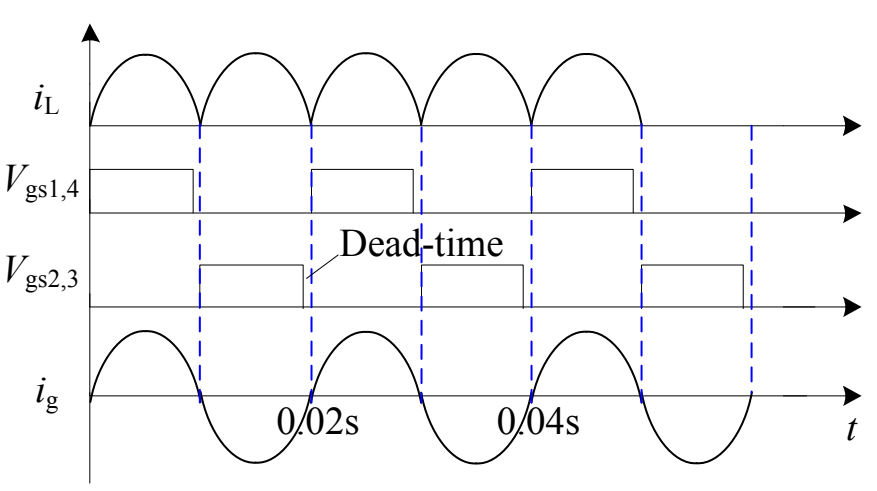

(b) 
As shown in Figures 10 and 12a, BSS-FBC operates in accordance with the order of mode 1-mode 2-mode 3-mode 4 circularly in discharging mode. When the switches $\mathrm{S}_{9}, \mathrm{~S}_{12}$ or $\mathrm{S}_{10}, \mathrm{~S}_{11}$ are turned on (discharging mode 1 or 3 in Figure 10), the current of the inductor $L$ increases linearly, and the inductor absorbs energy at the same time. When $S_{9}-S_{12}$ are all turned off (discharging mode 2 or 4 in Figure 10), the inductor $L$ releases energy through the freewheeling diodes of $\mathrm{S}_{5}-\mathrm{S}_{8}$, and its current decreases linearly. In the positive half of the grid voltage line cycle, $\mathrm{S}_{1}$ and $\mathrm{S}_{4}$ are turned on; and in the negative half $S_{2}$ and $S_{3}$ are turned on. In order to prevent short-circuit, a dead time must be added to the driving pulses of $\mathrm{S}_{1}-\mathrm{S}_{4}$ during which the inductor current flows into the dead-time capacitor. A passive snubber $\left(R_{C}, D_{C}\right.$ and $\left.C_{C}\right)$ is added to eliminate the voltage spikes caused by reverse recovery of the wheeling diodes of $\mathrm{S}_{5}-\mathrm{S}_{8}$. In the discharging mode, this topology is equivalent to a buck converter, and the input-output relationship can be expressed as:

$$
U_{\mathrm{O}}=\frac{1}{N D} U_{\mathrm{I}}
$$

In both the charging and discharging modes, unlike other typical topologies for which there is a specific range or condition for soft-switching, the BSS-FBC has only four active switches operating at high frequency and only one stage from the aspect of control, resulting in simplified control design and implementation.

\subsection{Harmonic Characteristics Analysis}

As the interface of energy interaction, the bidirectional charger must satisfy the requirements of current harmonics specified in several international standards, such as IEEE 519-1992 [72] and IEC 61000-3-2 [50]. Excessive high-order harmonic currents injected into the power systems with a small short-circuit capacity will have a detrimental effect on grid stability. As a result, it is necessary to reduce harmonics of interfacing bidirectional converters.

\subsubsection{PWM Modulation of the Topology}

Suppose that the grid voltage can be described as $u_{g}(t)=U_{g m} \sin \omega_{s} t$, where $U_{g m}$ is the peak value of the fundamental voltage for the grid and $\omega_{s}$ is the angular frequency of the fundamental voltage for the grid. According to the operational principles described before, the inductor current can be described as:

$$
i_{g}(t)= \begin{cases}i_{L}(t) & 2 k \pi \leq \omega_{s} t<2 k \pi+\pi \\ -i_{L}(t) & 2 k \pi+\pi \leq \omega_{s} t<2 k \pi+2 \pi\end{cases}
$$

and:

$$
L \frac{d i_{L}}{d t}= \begin{cases}U_{g m} \sin \omega_{s} t-u_{b c}(t) & 2 k \pi \leq \omega_{s} t<2 k \pi+\pi \\ -U_{g m} \sin \omega_{s} t-u_{b c}(t) & 2 k \pi+\pi \leq \omega_{s} t<2 k \pi+2 \pi\end{cases}
$$

It follows that:

$$
L \frac{d i_{g}}{d t}= \begin{cases}U_{g m} \sin \omega_{s} t-u_{b c}(t) & 2 k \pi \leq \omega_{s} t<2 k \pi+\pi \\ U_{g m} \sin \omega_{s} t+u_{b c}(t) & 2 k \pi+\pi \leq \omega_{s} t<2 k \pi+2 \pi\end{cases}
$$


If:

$$
u_{b c}{ }^{\prime}(t)= \begin{cases}u_{b c}(t) & 2 k \pi \leq \omega_{s} t<2 k \pi+\pi \\ -u_{b c}(t) & 2 k \pi+\pi \leq \omega_{s} t<2 k \pi+2 \pi\end{cases}
$$

then Equation (5) could be expressed as:

$$
L \frac{d i_{g}}{d t}=U_{g m} \sin \omega_{s} t-u_{b c}{ }^{\prime}(t)
$$

According to Equation (7) and the operational principles, in the positive half cycle of the grid voltage, the amplitude of $u_{b c}{ }^{\prime}(t)$ switches between $N U_{b}$ and 0 ; and in the negative half cycle, the amplitude of $u_{b c}{ }^{\prime}(t)$ switches between $-N U_{b}$ and 0 . Consequently, the PWM modulation mode of the proposed BSS-FBC is equivalent to a unipolar modulation of a single-phase PWM converter, as shown in Figure 13, where Figure 13a illustrates the PWM modulation mode of the BSS-FBC, and Figure 13b is the unipolar modulation of the single-phase PWM converter.

Figure 13. Modulation mode equivalent transformation of BSS-FBC and single-phase PWM converter with unipolar control: (a) PWM modulation mode of BSS-FBC; (b) Unipolar modulation of single-phase PWM converter.

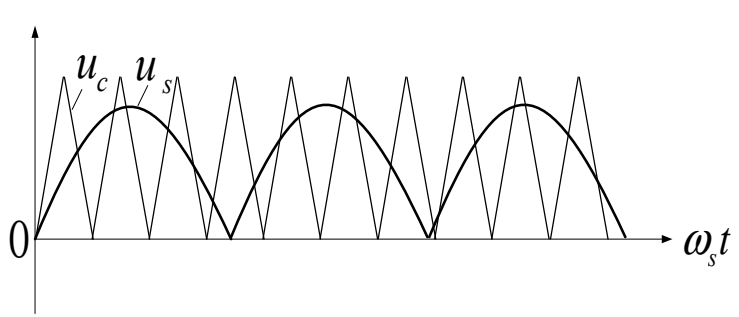

(a)

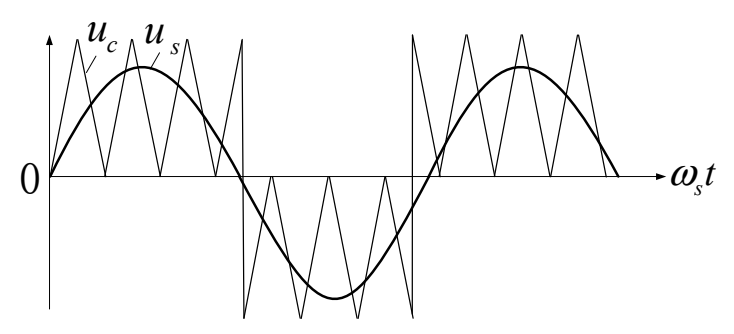

(b)

\subsubsection{Harmonic Analysis of Port Voltage $u_{b c}(t)$ of High-Frequency Switching Networks}

For the single-phase PWM converter with bipolar modulation, the port voltage of the high-frequency switching network can be expressed as [73]:

$$
\begin{aligned}
u_{b c}(t)= & M U_{d} \sin \left(\omega_{s} t-\varphi\right)+\frac{4 U_{d}}{\pi} \sum_{m=1,3,5, \ldots}^{\infty} \frac{1}{m} J_{0}\left(\frac{m \pi M}{2}\right) \sin \frac{m \pi}{2} \cos \left(m \omega_{c} t\right) \\
& +\frac{4 U_{d}}{\pi} \sum_{m=1,2, \cdots}^{\infty} \sum_{n= \pm 1, \pm 2, \ldots}^{ \pm \infty} \frac{1}{m} J_{n}\left(\frac{m \pi M}{2}\right) \sin \left(\frac{m+n}{2} \pi\right) \cos \left[m \omega_{c} t+n\left(\omega_{s} t-\varphi\right)-\frac{n \pi}{2}\right]
\end{aligned}
$$

where $U_{d}$ is the DC side voltage, $M$ is the modulation ratio, $M=U_{s} / U_{c}, U_{s}$ is the peak value of the modulation wave, $U_{c}$ is the peak value of the carrier, $N^{\prime}$ is the carrier ratio, $N^{\prime}=\omega_{s} / \omega_{c}$, $\omega_{s}$ is the angular frequency of the modulation wave, $m$ is the harmonic order of the carrier, $n$ is the harmonic order of the modulation wave, $\varphi$ is the phase angle of modulation, $J$ are the Bessel functions.

Similarly, to the single-phase PWM converter with unipolar modulation, the port voltage of the high-frequency switching network can be expressed as [73]: 


$$
\begin{aligned}
u_{b c}(t)= & M U_{d} \sin \left(\omega_{s} t-\varphi\right) \\
& +\frac{2 U_{d}}{\pi} \sum_{m=1,2, \cdots}^{\infty} \sum_{n= \pm 1, \pm 3, \ldots}^{ \pm \infty} \frac{1}{m} J_{n}(m \pi M) \cos m \pi \sin \left[m \omega_{c} t+n\left(\omega_{s} t-\varphi\right)\right]
\end{aligned}
$$

As indicated in the Equation (8), to the single-phase PWM converter with bipolar modulation, the port voltage of the high-frequency switching network contains the fundamental component, carrier and its odd-order harmonics, carrier and sideband harmonics of $m$ order carrier harmonics. What indicated in Equation (9) is, to the single-phase PWM converter with unipolar modulation, the port voltage of the high-frequency switching network contains the fundamental component, sideband harmonics of even-order carrier harmonics. Through the Equations (8) and (9), it can be concluded that the port voltage of the high-frequency switching network in the unipolar modulation mode does not contain the carrier and its odd-order harmonics or sideband harmonics of the carrier and its odd-order harmonics. Therefore, the harmonic components of $u_{b c}(t)$ in the unipolar modulation mode are less than these in the bipolar modulation mode.

\subsubsection{Harmonic Comparison and Analysis of Grid Current $i_{g}(t)$}

Assuming that the grid voltage $u_{g}(t)$ only contains the fundamental component, namely the grid voltage is $u_{g}(t)=U_{g m} \sin \omega_{s} t$. For the single-phase PWM converter with unipolar modulation, to the second term in the Equation (9), we have:

$$
m \omega_{c} t+n\left(\omega_{s} t-\varphi\right)=\left(m N^{\prime}+n\right) \omega_{s} t-n \varphi
$$

Therefore, the carrier and its upper and lower frequency harmonics of $m$ order harmonics can be considered as the $m N^{\prime}+n$ order harmonics of the modulation wave. The $m N^{\prime}+n$ order modulation wave harmonic components of the grid current $i_{g}(t)$ satisfy:

$$
L \frac{d i_{g_{m N^{\prime}+n}}}{d t}=u_{b c_{m N^{\prime}+n}}-u_{g_{m N^{\prime}+n}}
$$

Equation (9) can be rewritten as:

$$
u_{b c_{m N^{\prime}+n}}(t)=\frac{2 U_{d}}{m \pi} J_{n}(m \pi M) \cos m \pi \sin \left[m \omega_{c} t+n\left(\omega_{s} t-\varphi\right)\right]
$$

Since the grid voltage $u_{g}(t)$ only contains the fundamental component, $u_{g_{m N^{\prime}+n}}=0$. Substituting Equation (12) into Equation (11) and solving the new equation, we obtain:

$$
i_{g_{m X^{\prime}+n}}=\frac{2 U_{d}}{m \pi L} J_{n}(m \pi M) \frac{\cos m \pi}{m \omega_{c}+n \omega_{s}} \sin \left[m \omega_{c} t+n\left(\omega_{s} t-\varphi\right)-\frac{\pi}{2}\right]
$$

Define the fundamental component of the grid current $i_{g_{1}}(t)=I_{g_{1} m} \sin \omega_{s} t$, where $I_{g_{1} m}$ is the fundamental peak value of the grid current. Thus, the grid current in the unipolar modulation mode can be written as:

$$
\begin{aligned}
i_{g}(t)= & I_{g_{1} m} \sin \omega_{s} t \\
& +\frac{2 U_{d}}{\pi L} \sum_{m=1,2, \cdots}^{\infty} \sum_{n= \pm 1, \pm 3, \ldots}^{ \pm \infty} \frac{1}{m} J_{n}(m \pi M) \frac{\cos m \pi}{m \omega_{c}+n \omega_{s}} \sin \left[m \omega_{c} t+n\left(\omega_{s} t-\varphi\right)-\frac{\pi}{2}\right]
\end{aligned}
$$


Similarly, the equation of the grid current in the bipolar modulation mode can be obtained by Equations (8) and (11):

$$
\begin{aligned}
i_{g}(t)= & I_{g_{1} m} \sin \omega_{s} t+\frac{4 U_{d}}{\pi L} \sum_{m=1,3,5, \ldots}^{\infty} \frac{1}{m} J_{0}\left(\frac{m \pi M}{2}\right) \frac{\sin \frac{m \pi}{2}}{m \omega_{c}} \sin \left(m \omega_{c} t\right) \\
& +\frac{4 U_{d}}{\pi L} \sum_{m=1,2, \cdots}^{\infty} \sum_{n= \pm 1, \pm 2, \ldots}^{ \pm \infty} \frac{1}{m} J_{n}\left(\frac{m \pi M}{2}\right) \frac{\sin \left(\frac{m+n}{2} \pi\right)}{m \omega_{c}+n \omega_{s}} \cos \left[m \omega_{c} t+n\left(\omega_{s} t-\varphi\right)-\frac{n \pi}{2}\right]
\end{aligned}
$$

Through Equations (14) and (15), it's obvious that the grid current in the unipolar modulation mode doesn't contain the carrier and its odd-order harmonics, compared with these in the bipolar modulation mode. Therefore, the harmonic components of the grid current in the unipolar modulation mode are less than these in the bipolar modulation mode.

According to the analysis in Section 3.3.1., the PWM modulation mode of the BSS-FBC is equivalent to a unipolar modulation of the single-phase PWM converter. As a result, by Equation (14) it can be deduced that the grid current of the BSS-FBC only contains the fundamental component, carrier and its harmonics' sideband harmonic components. According to the operational principles, the carrier frequency of the BSS-FBC is twice that of the single-phase PWM converter with unipolar modulation, namely $\omega_{c}{ }^{\prime}=2 \omega_{c}$. Together with Equation (14), this implies that the harmonics of the grid current only contain the sideband harmonic components of the carrier's $m=2 k$ order harmonics, and the sideband harmonic components of the carrier's $m=2 k-1$ order harmonics are eliminated, where $k=1,2,3, \cdots$.

In conclusion, at the same switching frequency, the harmonic contents of the grid current satisfy BSS-FBC < single-phase PWM converter with unipolar modulation $<$ single-phase PWM converter with bipolar modulation.

\subsubsection{Verification of Harmonic Analysis of Grid Current $i_{g}(t)$}

To verify the conclusions of the harmonic characteristics analysis, we use PLECS to carry out simulation studies on the BSS-FBC, single-phase PWM converter with unipolar modulation, and single-phase PWM converter with bipolar modulation. Specifications and main parameters of the simulation were chosen as follows: the inductance $L=2 \mathrm{mH}$, the switching frequency $10 \mathrm{kHz}$, the voltage of the battery side $488 \mathrm{~V}$ (the battery voltage of the BSS-FBC is $444 \mathrm{~V}$, and its transformer ratio is 1.1), the peak current of the grid side $21 \mathrm{~A}$. The grid-side current spectrum waveforms of three cases are shown in Figure 14, where (a) is for the BSS-FBC, single-phase PWM converter with unipolar, and bipolar control from top to bottom; (b) is the grid current spectrum analysis for an partial view from which it can be seen the high-order harmonics contributes more to total harmonic distortion (THD) compared to the small-value low-order harmonics.

Figure 14 confirms that the harmonic components of the PWM converter with unipolar modulation are zero at the carrier and carrier's odd frequency, such as $10 \mathrm{kHz}, 30 \mathrm{kHz}, 50 \mathrm{kHz}$, etc. Also, the harmonic components of the PWM converter with bipolar modulation are not zero at those frequencies, and the harmonic components of BSS-FBC are zero at the carrier and carrier's odd frequency, such as $20 \mathrm{kHz}, 60 \mathrm{kHz}$, etc. Compared to the single-phase PWM converter with unipolar 
modulation, the harmonic components of the BSS-FBC are zero at the sideband of the unipolar modulated PWM converter's carrier and its odd harmonics (such as the sideband of $10 \mathrm{kHz}, 30 \mathrm{kHz}$, $50 \mathrm{kHz}$, etc.). These are consistent with the analysis results.

Figure 14. Grid-side current spectrum waveforms of BSS-FBC, single-phase PWM converter with unipolar and bipolar control: (a) Normal view; (b) Partial view.

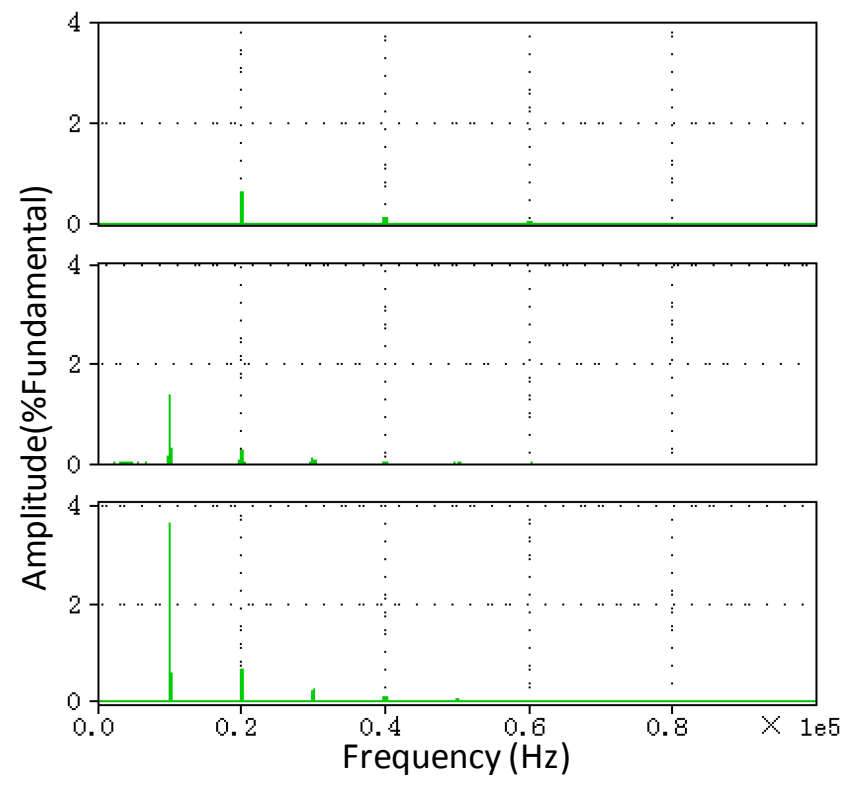

(a)

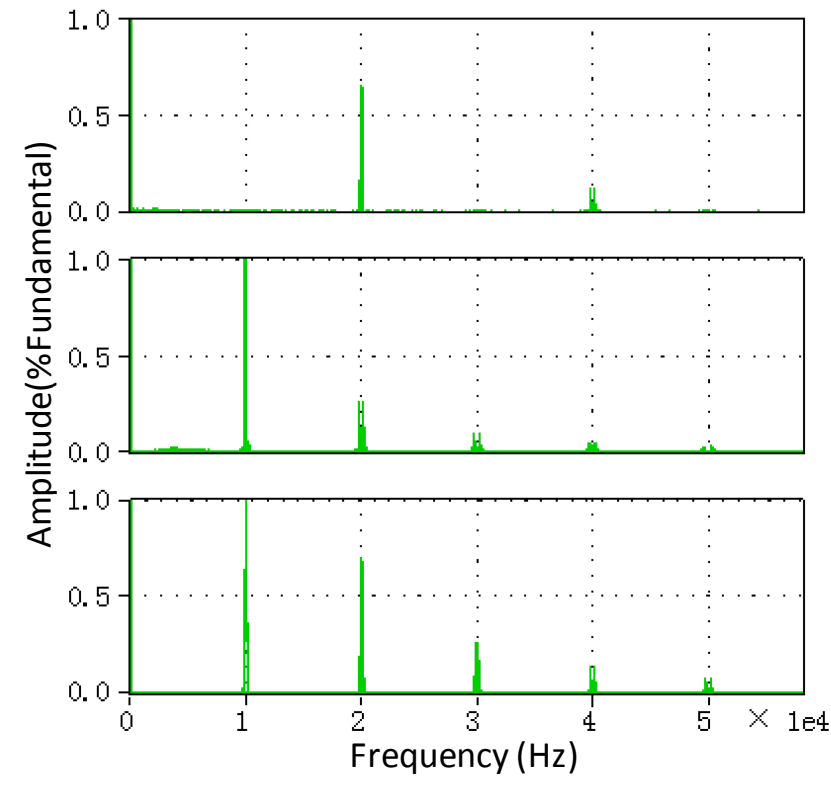

(b)

Figure 15. Grid-side current waveforms of BSS-FBC, single-phase PWM converters with unipolar and bipolar control: (a) Line-frequency view; (b) High-frequency view.
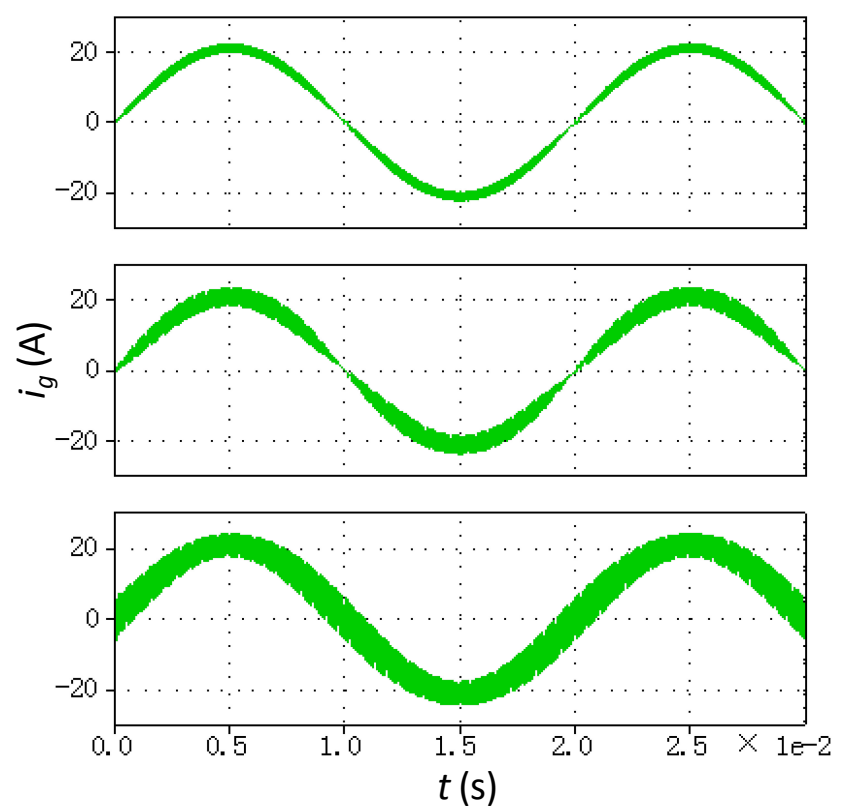

(a)

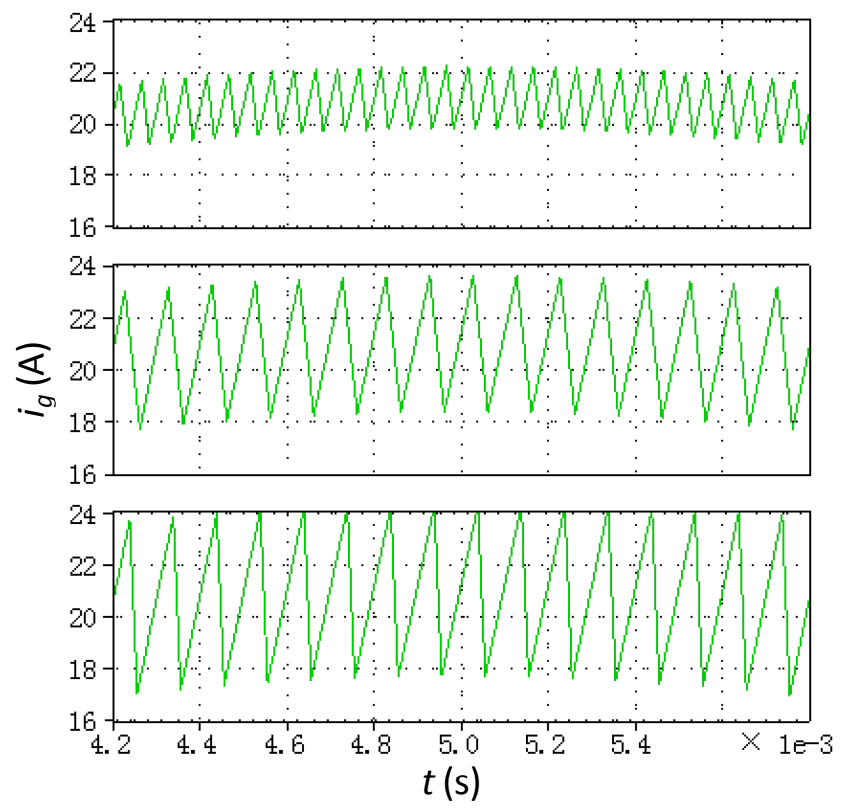

(b) 
Figure 15 is the grid-side current waveforms of the BSS-FBC, PWM converters with unipolar modulation and bipolar modulation from top to bottom. As can be seen in this figure, under the same inductance value and switching frequency, the grid-side current ripples of the BSS-FBC are smaller than these of the single-phase PWM converter. The total harmonic distortion (THD) of the BSS-FBC, single-phase PWM converters with unipolar and bipolar control are $0.71 \%, 2 \%$, and 2.58\%, respectively, which verifies the analysis results of harmonic characteristics. Furthermore, it can be deduced that the power loss, EMI and the volume of the inductor are reduced to various extents under the same inductance value and switching frequency.

\subsection{Dynamic Characteristics}

To support the main functions of $\mathrm{V} 2 \mathrm{G}$ such as frequency regulation, fast response is essential for compensating rapid load fluctuations, so that the negative effects on the unit caused by ramping or alternately load rising and falling can be promptly attenuated [74]. According to the operational principles, the BSS-FBC has two operational modes (the charging mode and discharging mode). In this section, a dynamic small-signal model of the BSS-FBC is developed, and the compensator is designed based on the dynamic characteristic analysis.

Assume that the converter operates under ideal conditions, all switches are ideal, ignoring saturation voltage (or on resistance), cut-off current, and switch delay time. The high-frequency transformer $T$ is also ideal, ignoring its magnetizing inductance and leakage inductance. Thus, there is no snubber circuit and dead-time capacitor in the BSS-FBC. In addition it is assumed that the frequency of small-signal perturbations is much smaller than the switching frequency of the converter, and the amplitude of small-signal perturbations is much smaller than that of the steady-state value.

Figure 16a,b show the equivalent switch network of the BSS-FBC in the charging and discharging modes, respectively, where $r$ is the equivalent resistance of the inductor and line, and $u_{o}$ is the voltage of the capacitor $C_{o}$. To facilitate the analysis of the characteristics of power supply in the charging mode, $R_{L}$ is the virtual resistive load in the charging mode. The positive directions of the voltage and current during the dynamic model analysis process are marked in Figure 16.

Figure 16. Equivalent switching network of BSS-FBC: (a) Charging mode; (b) Discharging mode.

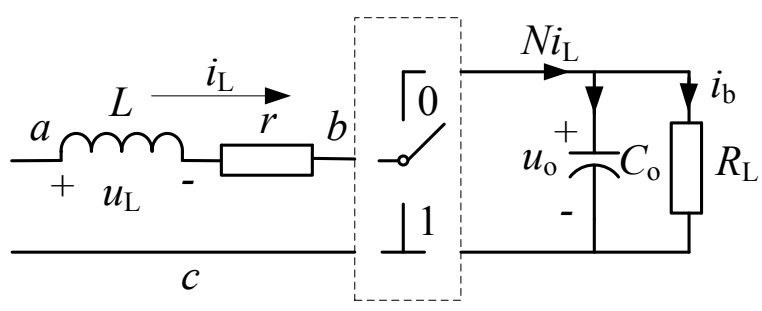

(a)

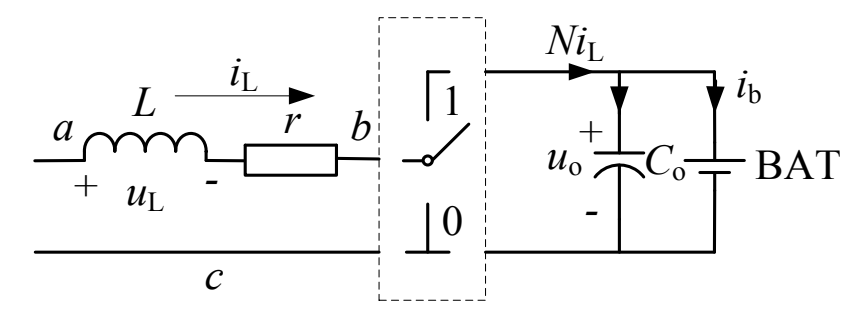

(b)

Based on the operational processes of the primary side and secondary side of the high-frequency transformer, we can establish the large-signal model of the BSS-FBC by the state space averaging method. After simplification, the state equations in the charging mode and discharging mode can be described as follows: 


$$
\left\{\begin{array}{l}
L \frac{d i_{L}}{d t}=\overline{u_{a c}}-D^{\prime} \overline{N U_{b}}-i_{L} r \\
C \frac{d u_{o}}{d t}=D^{\prime} N i_{L}-\frac{\overline{U_{b}}}{R_{L}}=D^{\prime} N i_{L}-\overline{i_{b}}
\end{array}\right.
$$

where $D^{\prime}=1-D$ is the duty cycle, $\overline{u_{a c}}, \overline{N U_{b}}, \overline{U_{b}}$ are the average voltages of points a and c, the average voltages of points $\mathrm{b}$ and $\mathrm{c}$, the average voltage of $u_{o}$ in the inductor operational cycle respectively.

Since the DC operating point of the BSS-FBC generally contains AC components near the line frequency, the commonly used small-signal analysis method for DC/DC converters is not applicable to this situation. In [75,76], a small-signal modeling method suitable for PWM controlled high power factor $\mathrm{AC} / \mathrm{DC}$ converters was introduced. According to this method, the control-to-inductor-current transfer function can be derived as follows:

$$
\begin{aligned}
G_{i d}(s) & =\frac{\hat{i}_{L}(s)}{\hat{d}(s)}=\frac{N U_{o} R_{L} C s+2 N U_{o}}{R_{L} L C s^{2}+\left(L+r C R_{L}\right) s+R_{L} D^{\prime 2} N^{2}+r} \\
& =\frac{2 N U_{o}}{R_{L}(1-D)^{2} N^{2}} \cdot\left(1+\frac{R_{L} C s}{2}\right) /\left(1+\frac{L s+r}{R_{L}(1-D)^{2} N^{2}}+\frac{L C s^{2}+r C s}{(1-D)^{2} N^{2}}\right)
\end{aligned}
$$

where $D^{\prime}=1-D=\frac{u_{a b r m s}}{N U_{o}}$ is the RMS value of the duty cycle in the line-frequency cycle, and $u_{a b r m s}$ is the RMS value of $u_{a b}$.

According to [75-77], when ignoring the perturbation on the capacitor voltage $\hat{u}_{o}$, the load is a constant voltage source, and by high-frequency approximation, Equation (17) can be simplified to:

$$
G_{i d}(s)=\frac{\hat{i}_{L}(s)}{\hat{d}(s)}=\frac{N U_{o}}{L s+r}
$$

Since the frequency of the modulation wave is much smaller than that of the carrier, the modulation signal $u_{m}$ can be considered as a constant in one carrier cycle. From the aforementioned conclusion that the PWM modulation mode of the BSS-FBC is equivalent to a unipolar modulation of the single-phase PWM converter, by the geometric similarity principle it is easy to get:

$$
D=\frac{u_{m}}{U_{t r i}}
$$

where $U_{t r i}$ is the amplitude of the triangular carrier signal, while the Equation (19) is independent of the operational modes of the BSS-FBC.

Taking into consideration of the PWM modulation process and delay effect, the PWM conversion link is equivalent to a first-order inertia link with time constant $T_{P W M}$. Based on the Equations (18) and (19), along with the operational principles of the BSS-FBC, after simplification the current loop of the PI controlled BSS-FBC is shown in Figure 17, where, $K_{p}$ is the proportional gain of the current loop PI compensator, $K_{i}$ is the integral coefficient of the current loop PI compensator, $K_{P W M}$ is the equivalent gain of the PWM conversion bridge whose value is proportional to the sampling gain of the inductor current and inversely proportional to the amplitude of the triangular carrier signal. As shown in Figure 17, the open-loop transfer function of the current loop without compensation is given by: 


$$
G_{o i}(s)=\frac{K_{P W M}}{T_{P W M} s+1} \cdot \frac{1}{L s+r}
$$

If $K_{P W M}=10, T_{P W M}=0.1 \mathrm{~ms}, L=2 \mathrm{mH}, r=0.1 \Omega$, then the Bode diagram of the open-loop transfer function without compensation (Figure 18a) and its step response (Figure 18b) can be obtained.

Figure 17. Current loop control block diagram of BSS-FBC.

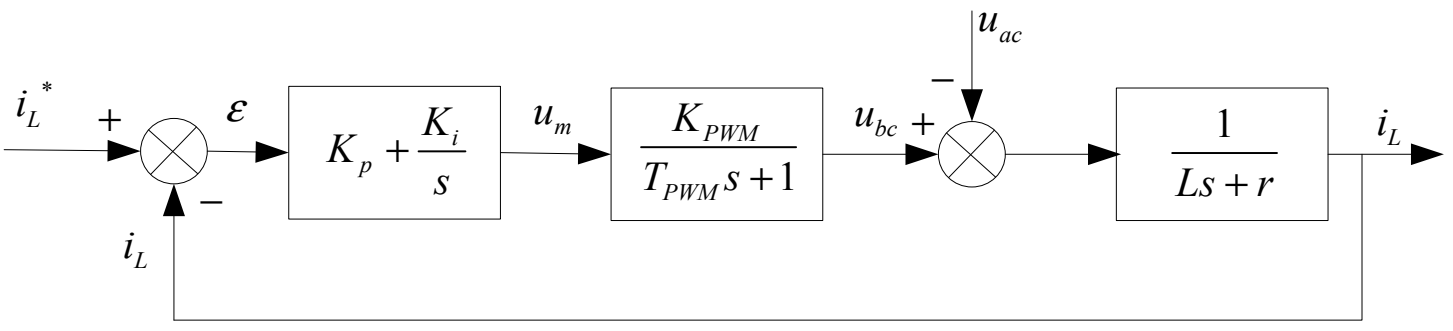

Figure 18. Open loop dynamic characteristic of current loop without compensator: (a) Bode diagram; (b) Step response.

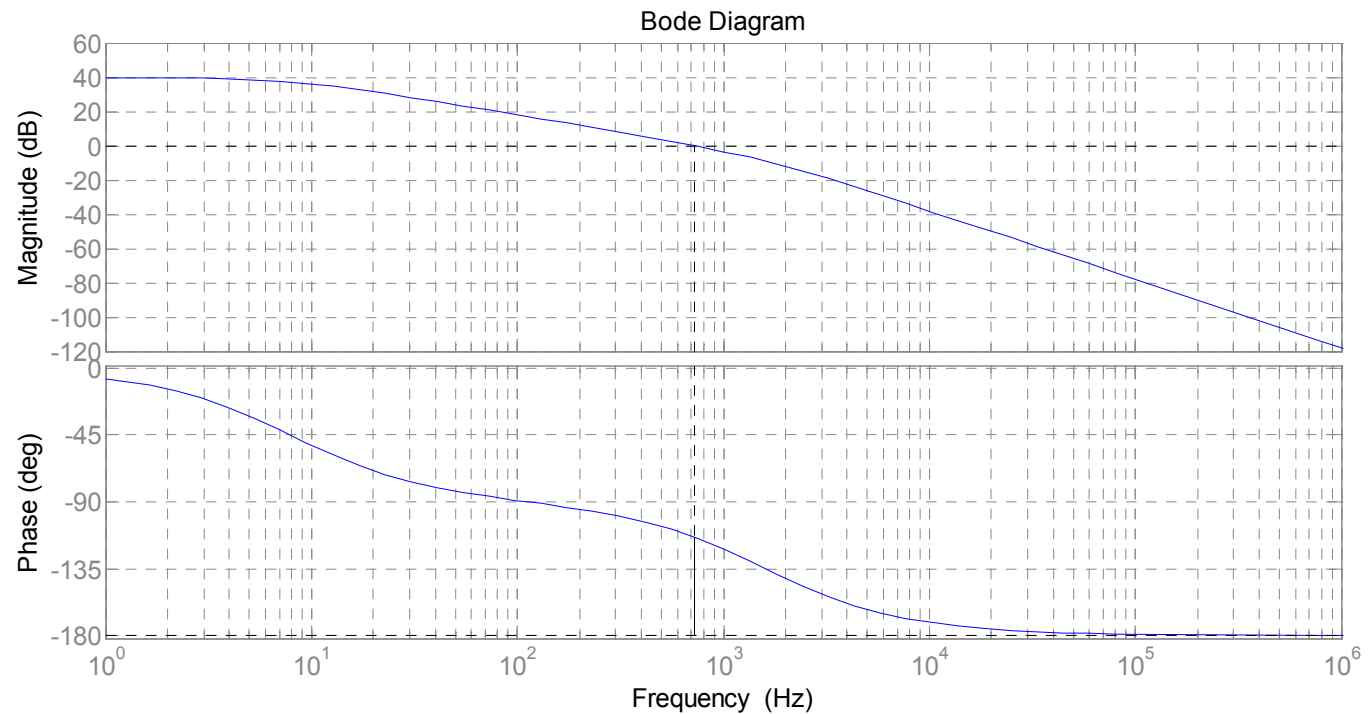

(a)

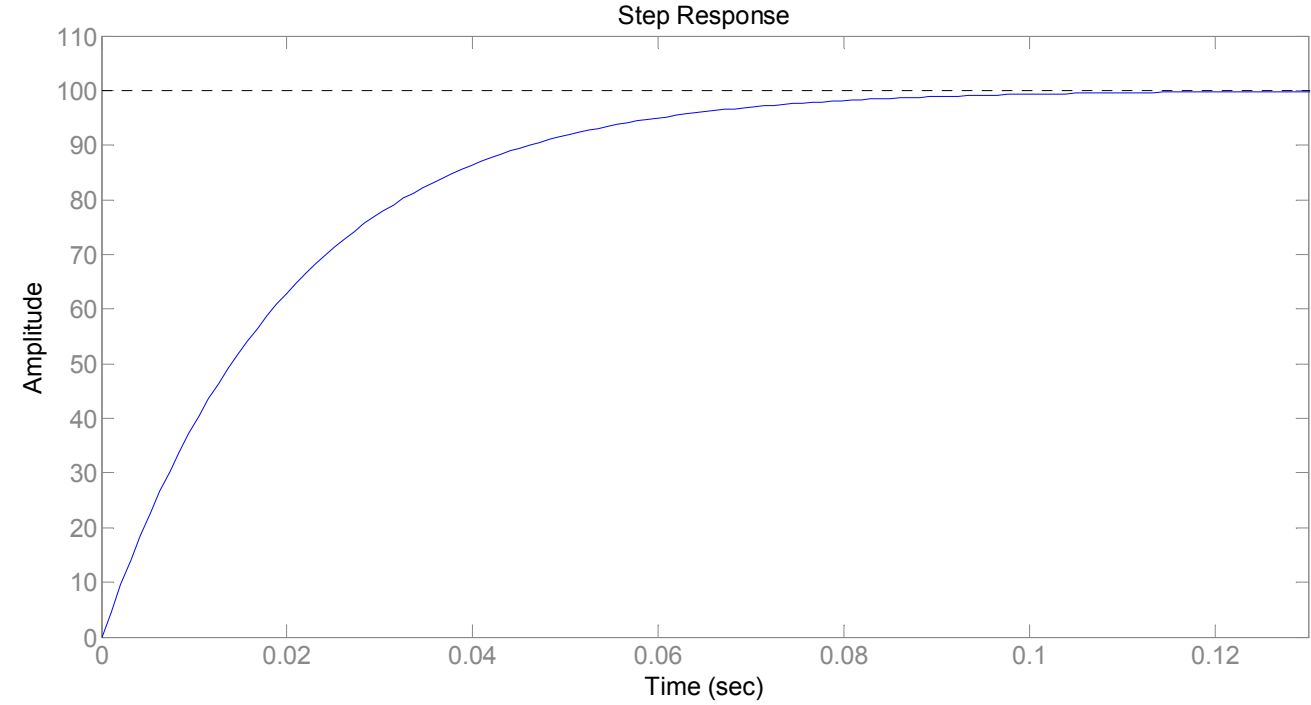

(b) 
As can be seen from Figure 18a, the open-loop inner current loop system of the BSS-FBC is stable. Its bandwidth is $7.94 \mathrm{~Hz}$ without compensation. Obviously, the bandwidth of the inner loop without compensation is unable to meet the rapidity requirement that the inductor current tracks the reference signal. Figure 18b illustrates that there is a steady-state error in the inner current loop open-loop system without compensation, and step response rise time is about $0.12 \mathrm{~s}$.

Based on the above analysis, to get the high power quality of the grid current, a compensator must be designed for the inner current loop. Consequently, the common proportional integral (PI) controller is adopted as the compensator. The open-loop transfer function of the current loop is:

$$
G_{o p i}(s)=G_{P I}(s) G_{o i}(s)=\frac{K_{p} s+K_{i}}{s} \cdot \frac{K_{P W M}}{T_{P W M} s+1} \cdot \frac{1}{L s+r}
$$

In order to obtain the rapidity of inner loop current tracking, the system is regulated to a typical Type 1 system which needs to use the zero of the PI controller to eliminate the pole of the open-loop transfer function, resulting in:

$$
\frac{K_{p}}{K_{i}}=\frac{L}{r}
$$

Then the close-loop transfer function of the current loop is derived as:

$$
G_{o c i}(s)=\frac{\frac{K_{p} K_{P W M}}{L T_{P W M}}}{s^{2}+\frac{1}{T_{P W M}} s+\frac{K_{p} K_{P W M}}{L T_{P W M}}}
$$

Therefore:

$$
\left\{\begin{array}{l}
2 \zeta \omega_{n}=\frac{1}{T_{P W M}} \\
\omega_{n}{ }^{2}=\frac{K_{p} K_{P W M}}{L T_{P W M}}
\end{array}\right.
$$

where $\zeta$ is the damping ratio, $\omega_{n}$ is the natural frequency. According to the typical tuning method of parameters in the Type 1 system, the damping ratio is selected to be 0.707 . Thus, based on Equations (22) and (24) the parameters of the PI controller are:

$$
\left\{\begin{array}{l}
K_{p}=\frac{L}{2 K_{P W M} T_{P W M}} \\
K_{i}=\frac{r}{2 K_{P W M} T_{P W M}}
\end{array}\right.
$$

The close-loop Bode diagram of the current loop with compensator for the new topology is shown in Figure 19a, and its step response is shown in Figure 19b. It can be observed that the bandwidth of the inner current loop is now $1125 \mathrm{~Hz}$ which is eleven times the fundamental frequency. There is no amplitude attenuation at the fundamental frequency $(100 \mathrm{~Hz})$, and the phase shift is only $7.28^{\circ}$. Under the unit step signal, there is no steady-state error in the inner current loop with compensator, and the 
rise time of step response is about $1.1 \mathrm{~ms}$, so that the dynamic response has been greatly improved compared to the performance without compensator in Figure $18 \mathrm{~b}$.

According to the harmonic analysis, it is obvious that with the same ripple factor of the inductor current and under the same switching frequency, the value of the inductor $L$ can be chosen smaller in the new topology, which will result in better dynamic characteristics. In this situation, Figure 19 also indicates that the new topology has better dynamic performance than the single-phase PWM converter whose rise time of step response is about $2 \mathrm{~ms}$, due to the wider bandwidth and faster response.

Figure 19. Close loop dynamic characteristics of current loop with compensator for the new topology and the single-phase PWM converter: (a) Bode diagram; (b) Step response.

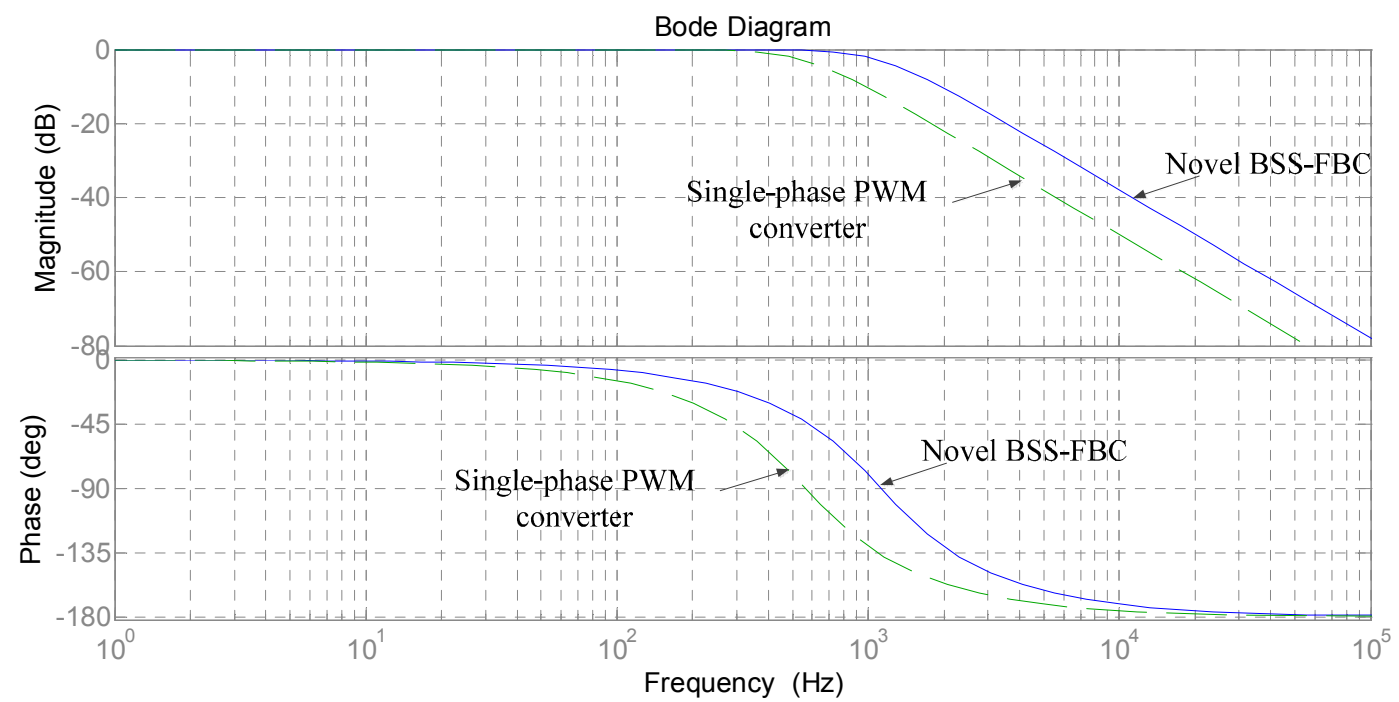

(a)

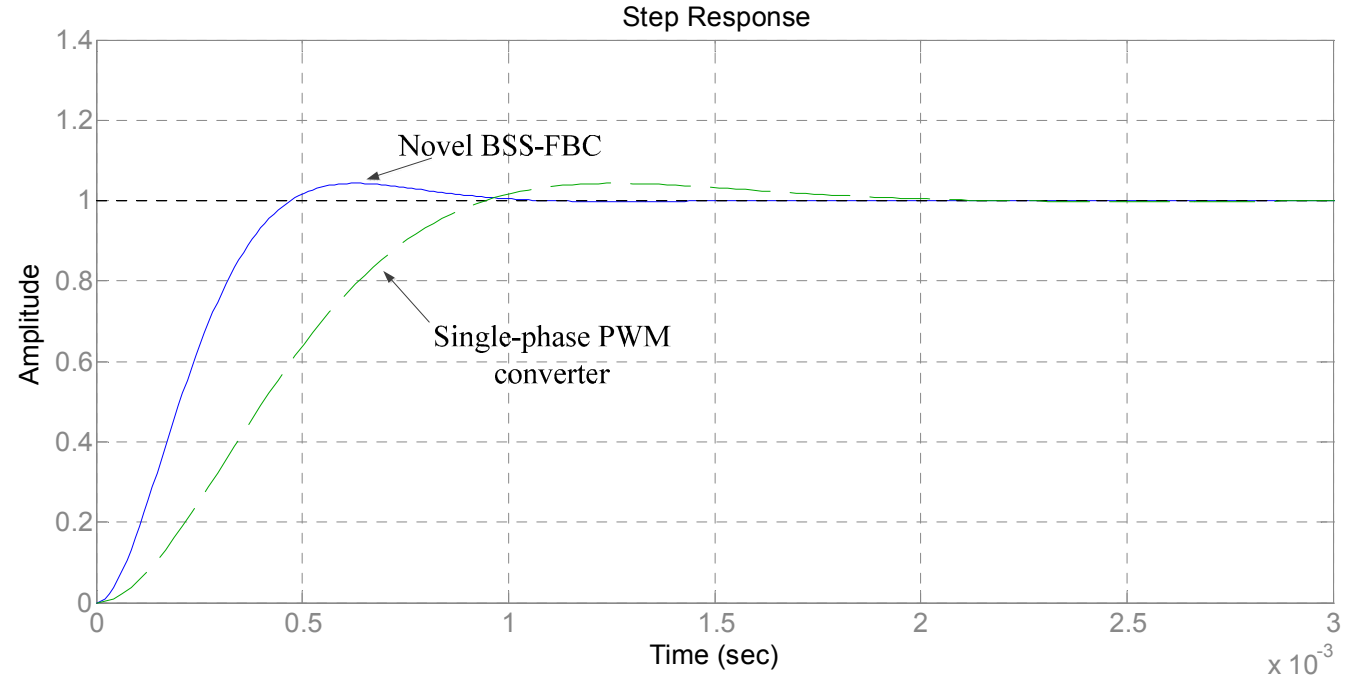

(b)

\section{Design Considerations}

\subsection{High-Frequency Transformer}

The high-frequency transformer $T$ of the BSS-FBC provides galvanic isolation and achieves the matching of the input voltage and output voltage over a wide voltage range of the battery pack. 
From the minimum voltage of the battery pack and the condition required for the inversion, according to the Equation (1) the turn ratio of transformer $T$ must satisfy:

$$
N \geq \max \left\{\frac{U_{g m_{\max }}}{U_{b_{\min }}\left(1-D_{\min }\right)}, \frac{U_{g m_{\max }}+\Delta U}{U_{b_{\min }}}\right\}
$$

where $U_{b_{\min }}$ is the minimum voltage of the battery pack, $D_{\min }$ is the minimum duty cycle, $U_{g m_{\max }}$ is the maximum peak voltage of the grid considering the fluctuation range of the grid voltage. Since the BSS-FBC adopts PWM modulation, in order to guarantee its operation, the turn ratio of transformer also has to satisfy:

$$
N>\frac{U_{g m}}{M U_{b}}
$$

However, the modulation ratio $M$ is not easy to get, and usually a voltage margin $\Delta U$ is induced which is commonly bigger than $40 \mathrm{~V}$. For the design of the transformer $T$, we note that the leakage inductance should be reduced by choosing proper material and winding methods to improve the performance and overall efficiency of the BSS-FBC.

\subsection{Filtering Inductor}

The inductor is the key for harmonic current suppression and unity power factor operation. Its design needs to consider harmonic current suppression, transient current tracking, and many other factors. Since the harmonics are maximum in the peak of the inductor current, in order to suppress the current harmonics, the value of the inductor must satisfy:

$$
L \geq \frac{U_{g m}\left(N U_{b \max }-U_{g m}\right)}{\Delta i_{\max } N U_{b \max } f_{L}}
$$

where $\Delta i_{\max }$ is the maximum ripple current, $f_{L}$ is the high-frequency operational frequency of the inductor.

On the other hand, from the aspect of current transient behavior, the current changing rate is maximum at the time of grid-current zero-crossing so that the value of the inductor should be smaller to insure fast response of the grid-side current and satisfy:

$$
L \leq \frac{N U_{b \min }}{I_{g_{1} m} \omega}
$$

Therefore:

$$
\frac{U_{g m}\left(N U_{b \max }-U_{g m}\right)}{\Delta i_{\max } N U_{b \max } f_{L}} \leq L \leq \frac{N U_{b \min }}{I_{g_{1} m} \omega}
$$

\subsection{Battery-Side Storage Capacitor}

According to the operational principles of the BSS-FBC, ideally the two sides of the storage capacitor $C_{\mathrm{o}}$ are DC current and DC current with low-frequency AC components and high-frequency switching component separately. To illustrate, assume that the converter operates in the discharging mode. If the discharging current $i_{\mathrm{BAT}}$ is greater than the battery-side output current $i_{0}$, the capacitor 
stores the excess charges. On the contrary, if the discharging current $i_{\mathrm{BAT}}$ is less than the battery-side output current $i_{0}$, the required charges are provided by the capacitor, and the quantity of electricity is given by:

$$
Q=\int_{t_{1}}^{t_{2}}\left(N I_{g_{1} m} \sin \omega t-i_{\mathrm{BAT}}\right) d t
$$

where $t_{1}$ and $t_{2}$ are the corresponding times for two intersections $y_{1}(t)=i_{\mathrm{BAT}}$ and $y_{2}(t)=N I_{g_{1} m} \sin \omega t$ in Cartesian coordinates in $0.01 \mathrm{~s}$ period. If a $10 \%$ voltage ripple is considered, then the value of the capacitor should satisfy:

$$
C_{o} \geq \frac{Q}{U_{b \min } \cdot 10 \%}
$$

\subsection{Dead-Time Capacitor}

During the dead time $t_{d}$ in the discharging mode, the inductor current $i_{L}$ charges the dead-time capacitor $C_{1}$, and the inductor current is almost zero because of the unity power factor operation. During this time, the charged quantity of electricity into the capacitor is:

$$
Q=C_{1} \Delta U_{C_{1}}=I_{L d} t_{d}
$$

where $\Delta U_{C_{1}}$ is the voltage variation of the dead-time capacitor, $I_{L d}$ is the transient inductor current in the dead time.

After the dead time, the switches of the line-frequency side $\left(S_{1}\right.$ and $S_{4}$, or $S_{2}$ and $\left.S_{3}\right)$ are turned on, and the dead-time capacitor starts to discharge to the grid. The discharging current at this moment is:

$$
I_{d}=\frac{\Delta U_{C_{1}}}{2 R_{o n}}
$$

where $R_{o n}$ is the on-state resistance of the switch. If the maximum allowable value of the discharging current is $I_{d \max }$, from Equations (33) and (34) we have:

$$
C_{1} \geq \frac{I_{L d}}{2 R_{o n} I_{d \max }} t_{d}
$$

The inductor $L$ and the dead-time capacitor constitutes an LC low-pass filter, and its cutoff frequency is:

$$
f_{\text {cutoff }}=\frac{1}{2 \pi \sqrt{L C_{1}}}
$$

In order to suppress the high-order harmonics well, the cutoff frequency cannot be selected too high but should be much higher than the fundamental frequency. Generally the cutoff frequency is chosen greater than 10 times the fundamental frequency, less than $1 / 2$ of the switching frequency. Therefore, the value of the dead-time capacitor should satisfy:

$$
\frac{I_{L d}}{2 R_{o n} I_{d \max }} t_{d} \leq C_{1} \leq \frac{1}{L\left(2 \pi \times 10 f_{1}\right)^{2}}
$$


where $f_{1}$ is the fundamental frequency which is $100 \mathrm{~Hz}$ for the BSS-FBC. Because the dead time is very short and the inductor current is almost zero during this time, the energy stored in the dead-time capacitor is negligible and the capacitance of the dead-time capacitor is small, which can use ordinary film capacitors.

\section{Discussions}

From the previous analysis, it can be concluded that in comparison to the existing typical topologies, the new topology of this paper has the following advantages:

(1) Higher Power Density, Reduced Component Count, Smaller Size, Lighter Weight

One of the major drawbacks of the typical two-stage bidirectional converters is the presence of the bulky DC intermediate link capacitor [39]. The proposed novel topology eliminates the bulky and expensive DC link capacitor. Furthermore, the inductor in the bidirectional DC-DC converter stage is no longer needed due to the current source nature of this topology. As a result, the component count, size and weight of the converter are reduced, leading to improved power density. These advantages are of importance in resolving the main challenges for on-board bidirectional converters in V2G applications.

\section{(2) Cost Effectiveness}

Cost reduction has critical impact on realization of V2G. By eliminating the expensive DC link capacitors and special customized inductor from the typical two-stage topologies, the count of passive components is reduced significantly (there are only one inductor and one energy storage capacitor in the new topology). Accordingly, the cost of the bidirectional converter is reduced. Furthermore, all twelve active switches in the typical two-stage topologies operate under high voltage stress, whereas the switches $\mathrm{S}_{1}-\mathrm{S}_{4}$ in the new topology only operate under the grid voltage which is much lower than the voltages in the single-phase PWM converter who has the boost converter characteristic and the voltage stress of switches is equal to DC-side voltage of PWM converter. This lower voltage stress leads to lower grade active switches $\mathrm{S}_{1}-\mathrm{S}_{4}$, and hence much reduced cost.

\section{(3) Less Harmonics}

The PWM modulation mode of the BSS-FBC is similar to the unipolar modulation of the single-phase PWM converter. It has less harmonic components compared to the bipolar modulated single-phase PWM converter. Under the same inductance and switching frequency, the new topology has less harmonic components than unipolar modulated single-phase PWM converters.

\section{(4) Excellent Dynamic Characteristics}

Also, from the analysis of harmonics, it can be seen that compared with two-stage topologies using PWM converters as the current shaping stage, with the same ripple factor and switching frequency, the value of the inductor $L$ is smaller in the new topology. According to the control block diagram in Figure 17, the reduced value of the inductor will result in a positive effect on the dynamic characteristic. The response speed will be much faster since $L$ acts as an inertia time constant in the control loop. With a suitable design of the compensators for the control loops, the dynamic characteristics of the new topology can outperform the typical converters. 
(5) High Efficiency

Power efficiency is a key performance index for converters and is especially important for their V2G applications. The proposed topology has the advantage of high efficiency for several reasons: First, it has less passive components, leading to reduced losses, such as copper loss and core loss of inductor. Second, lower voltage stress of the switches $\mathrm{S}_{1}-\mathrm{S}_{4}$ means lower conduction losses on them. Third, comparing to the bipolar and unipolar modulated single-phase PWM converters in typical two-stage topologies, the new topology has less harmonic components and smaller inductor current ripples. This will reduce losses, EMI, and the size of inductor $L$ to a certain extent. Fourth, only four active switches in the new topology operate in high frequency, regardless if it is in the charging or discharging mode. In contrast, all twelve switches of typical two-stage topologies operate in high frequency, causing additional switching losses. Finally, the four switches $\mathrm{S}_{1}-\mathrm{S}_{4}$ in the new topology turn on and off at the zero-crossing point of the grid voltage and current and have no switching losses. We observe that although some switches in the DC-DC conversion stage of typical topologies realize soft-switching, they do not achieve this at the same switching time and soft-switching cannot be guaranteed during load changes or wide-range power flow variations.

(6) Increased Reliability, Simpler Control, and Reduced Complexity

Electrolytic capacitors used in DC intermediate links of two-stage topologies are likely to reduce converter reliability with their limited lifecycles. By eliminating this capacitor, the new topology can potentially enhance reliability. Usually, the grid-side current shaping stage and DC-DC conversion stage of typical two-stage converters are controlled separately by two micro control units using different control strategies. The new topology combines the two functions in one stage and only has four active switches to be PWM controlled (the switches $\mathrm{S}_{1}-\mathrm{S}_{4}$ are uncontrolled or driven by line-frequency pulses with constant duty cycle which don't need any active control). As a result, it uses only one micro control unit. Without loop interactions, the control design is also much simplified. As a result, the reliability is increased due to the simple control design and implementation and reduced sensors.

\section{Experimental Results}

\subsection{Specifications}

To verify the performance of the BSS-FBC, a laboratory prototype is developed and its control is implemented using one Freescale DSP chip. Figure 20 shows the prototype and its testbed. The specifications and main parameters of the prototype are chosen as Table 2.

Take inductor $L$ for instance, its value can be selected based on the Equation (30) in which the parameters is chosen as follow: the peak value of the grid voltage $U_{g m}$ is $311 \mathrm{~V}$, the turn ratio of transformer $N$ is 1.1 , the maximum battery voltage $U_{b \max }$ is $444 \mathrm{~V}$, the maximum ripple current $\Delta i_{\max }$ is $15 \%$ of the peak grid current and equal to $3.15 \mathrm{~A}, f_{L}$ is $20 \mathrm{kHz}, U_{b \min }$ is $336 \mathrm{~V}$, angular frequency $\omega$ is $314 \mathrm{rad} / \mathrm{s}$. Hence, $1.793 \mathrm{mH} \leq L \leq 56 \mathrm{mH}$. Consider the cost and the size of inductor, the value of $L$ is finally selected as $2 \mathrm{mH}$. 
Figure 20. Prototype and its testbed.

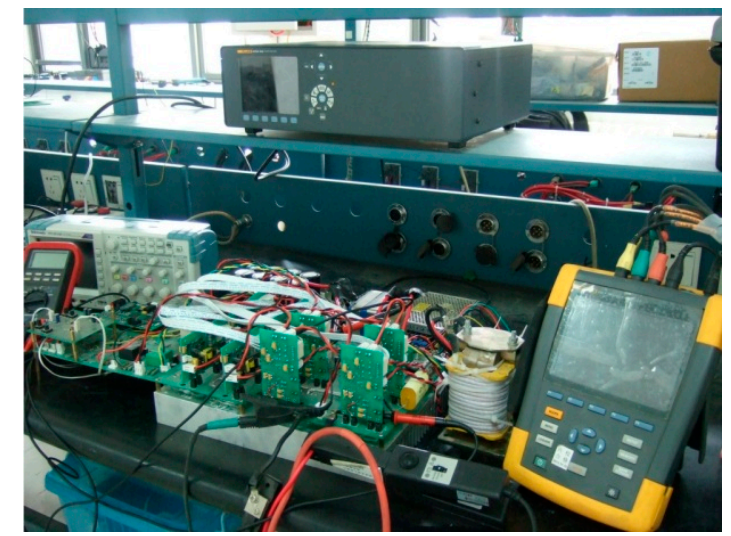

Table 2. Key parameters of the BSS-FBC prototype.

\begin{tabular}{lll}
\hline Parameters & Value & Unit \\
\hline Nominal Power & 3300 & $\mathrm{~W}$ \\
AC Grid Voltage (RMS) & $220 \pm 10 \%$ & $\mathrm{~V}$ \\
AC Grid Frequency & 50 & $\mathrm{~Hz}$ \\
Battery DC Voltage & 336 to 444 & $\mathrm{~V}$ \\
Switching Frequency of Active Switches & 10 & $\mathrm{kHz}$ \\
Inductor & 2 & $\mathrm{mH}$ \\
Energy Storage Capacitor & 4000 & $\mu \mathrm{F}$ \\
Turn Ratio of Transformer & 1.1 & - \\
Dead-time Capacitor & 3 & $\mu \mathrm{F}$ \\
Dead Time & 0.5 & $\mu \mathrm{s}$ \\
\hline
\end{tabular}

\subsection{Experimental Results}

Figure 21 shows the waveforms of the grid voltage and current at $100 \%$ rated power and $50 \%$ rated power in the charging mode, which illustrate that the grid current of the BSS-FBC tracks the grid voltage very well. The envelopes of these waveforms are sinusoidal with little harmonic distortions, and realize the unity power factor. Also, it can be seen that the harmonics increase slightly when the grid current decreases.

Figure 22 shows the high-frequency operating waveforms of the BSS-FBC in the charging mode. As can be seen in Figure $17 \mathrm{a}, \mathrm{S}_{5}$ and $\mathrm{S}_{6}$ turn on alternately in accordance with the operational principles. After the high-frequency switches turn off, the voltage stress of $\mathrm{S}_{5}$ and $\mathrm{S}_{6}$ is $488 \mathrm{~V}$, while the voltage spike at the moment of turning-off is reduced by the passive snubber. As shown in Figure 17b, when $\mathrm{S}_{5}-\mathrm{S}_{8}$ turn on, the inductor current increases linearly, the voltage of the freewheeling diode of $\mathrm{S}_{9}$ is $U_{b} / 2$. During the time when $\mathrm{S}_{5}$ and $\mathrm{S}_{8}\left(\right.$ or $\mathrm{S}_{6}$ and $\mathrm{S}_{7}$ ) conduct, the inductor current reduces linearly, and the voltage of the freewheeling diode of $\mathrm{S}_{9}$ is zero or $U_{b}$.

Figure 23 shows the waveforms of the grid voltage and current at $100 \%$ rated power and $50 \%$ rated power in the discharging mode. Similarly to that in the charging mode, the grid current of the BSS-FBC in the discharging mode also tracks the sinusoidal grid voltage very well, and it contains little harmonic contents and realizes the unity power factor operation. 
Figure 21. Grid voltage and current in the charging mode: (a) $u_{g}$ and $i_{g}$ at $100 \%$ rated power; (b) $u_{g}$ and $i_{g}$ at $50 \%$ rated power.

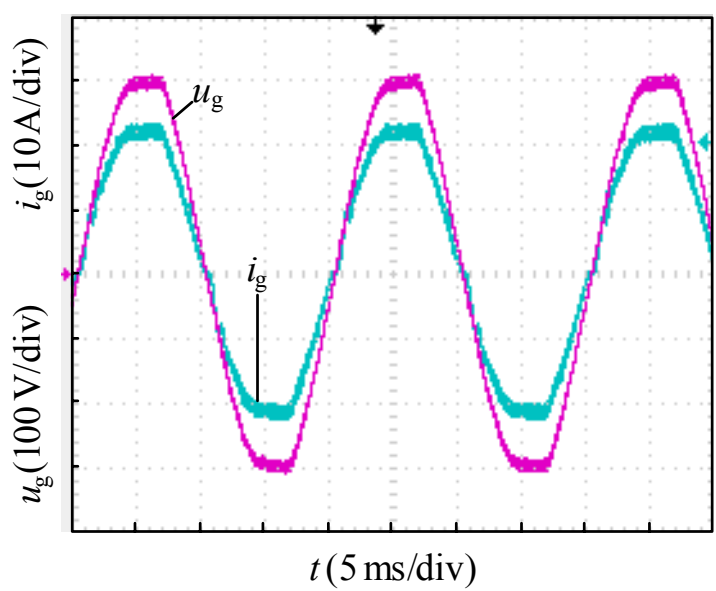

(a)

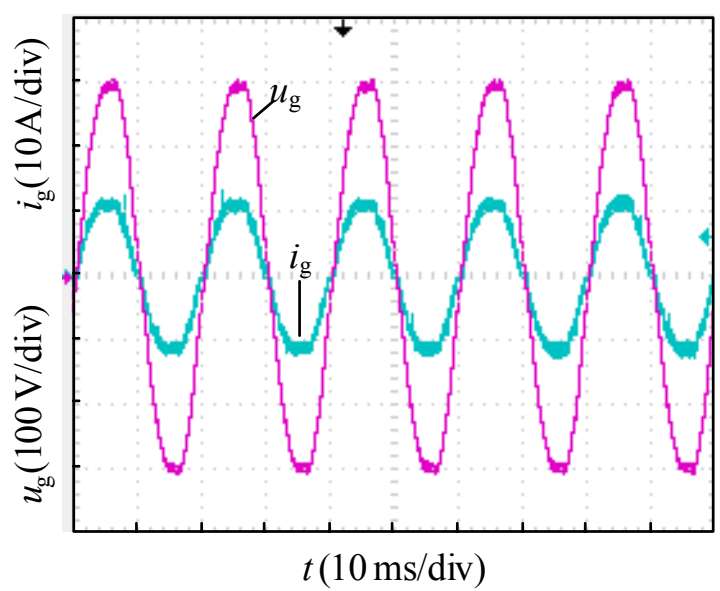

(b)

Figure 22. High-frequency operating waveforms of BSS-FBC in charging mode: (a) Driving pulse and voltage stress of $\mathrm{S}_{5}, \mathrm{~S}_{6}$; (b) Voltage stress of the freewheeling diode of $\mathrm{S}_{9}$, voltage stress of $\mathrm{S}_{5}$, and inductor current.

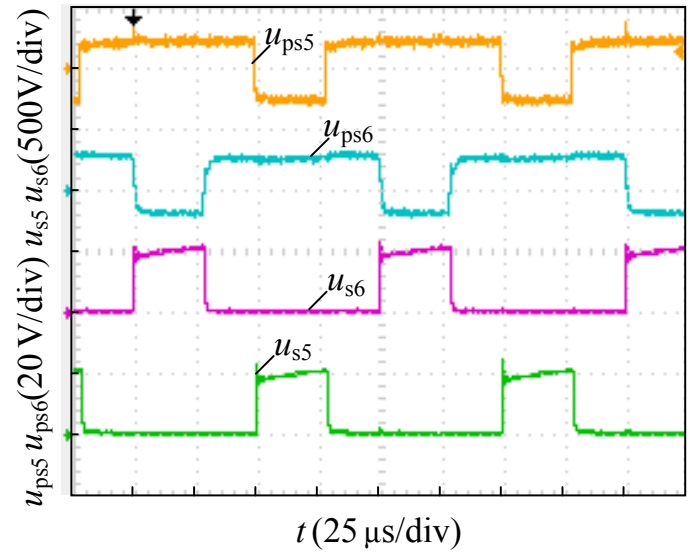

(a)

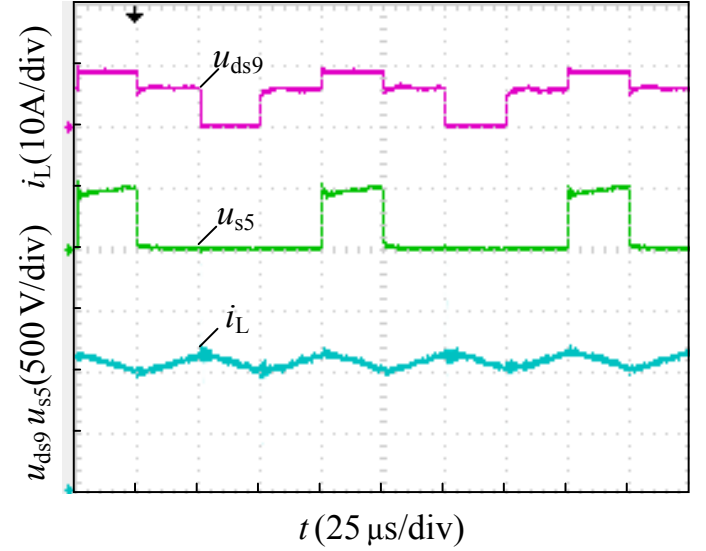

(b)

Figure 23. Grid voltage and current in the discharging mode: (a) $u_{g}$ and $i_{g}$ at $100 \%$ rated power; (b) $u_{g}$ and $i_{g}$ at $50 \%$ rated power.

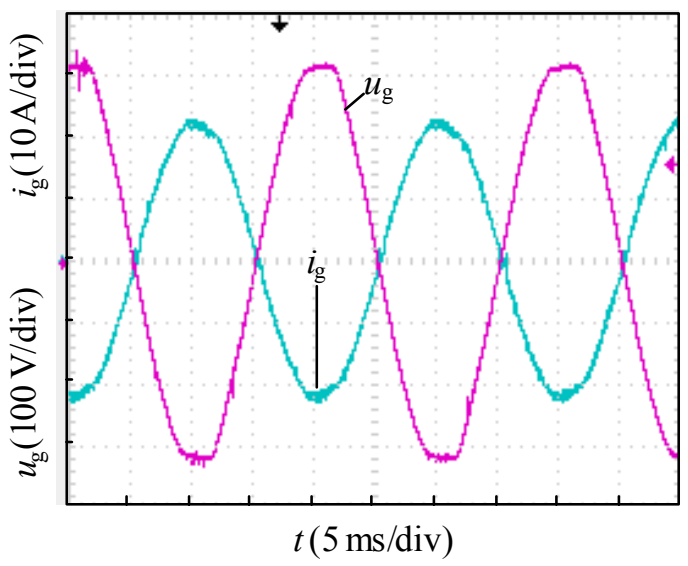

(a)

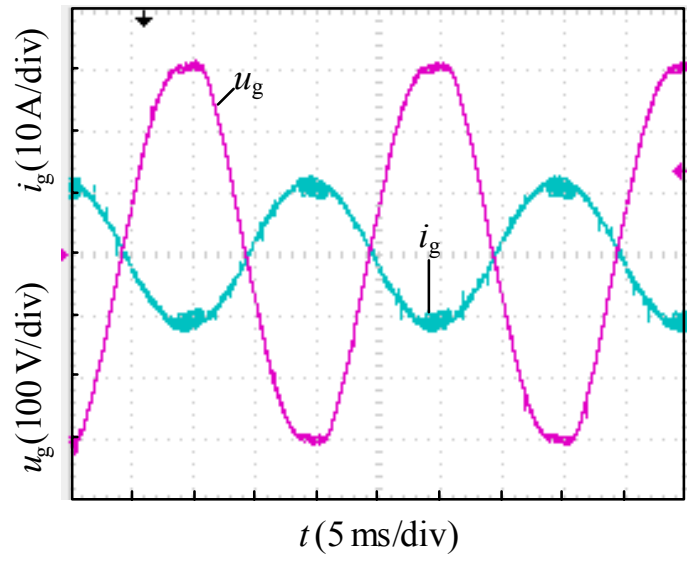

(b) 
Figure 24 shows the line-frequency operational waveforms of BSS-FBC in the discharging mode. In Figure 24a,c, $\mathrm{S}_{1}$ is driven and conducts in the positive half line cycle of the grid voltage, $\mathrm{S}_{2}$ is driven and conducts in the negative half line cycle of the grid voltage. Both of them turn on or off at the zero-voltage condition of the grid. Since the grid current at this time is also zero, there is no switching loss from $\mathrm{S}_{1}-\mathrm{S}_{4}$, and the voltage stress of these four switches is only equal to the grid voltage. Through the enlarged view (Figure 24b) at the zero-crossing point of the grid voltage in Figure 24a, it can be seen that there is a $0.5 \mu \mathrm{s}$ dead time added to the driving signals of $S_{1}$ and $S_{2}$ to avoid short circuit of bridge legs. Figure $24 \mathrm{~d}$ shows the voltage of the dead-time capacitor $C_{1}$ which is equal to the rectified grid voltage. There is no obvious fluctuation at the zero-crossing of the grid voltage.

Figure 24. High-frequency Line-frequency operating waveforms of BSS-FBC in discharging mode: (a) Grid voltage and driving pulse of $\mathrm{S}_{1}, \mathrm{~S}_{2}$; (b) Enlarged view at the zero-crossing point of grid voltage for grid voltage and driving pulse of $\mathrm{S}_{1}, \mathrm{~S}_{2}$; (c) Driving pulse and voltage stress of $\mathrm{S}_{1}, \mathrm{~S}_{2} ;$ (d) Voltage of dead time capacitor.

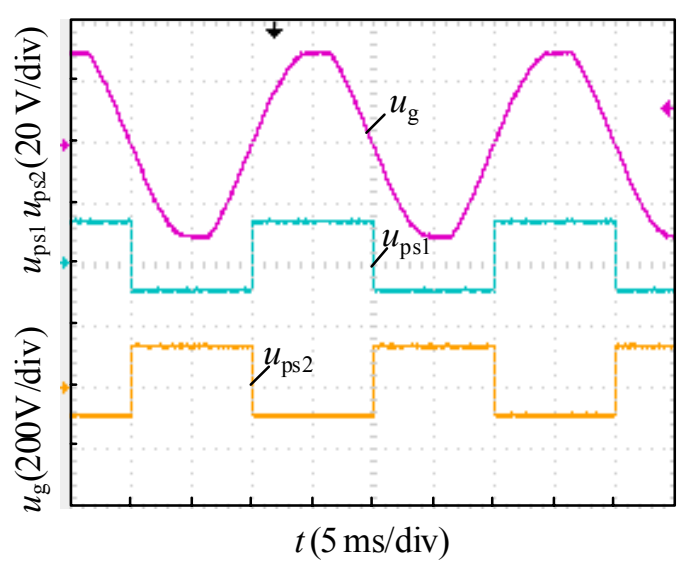

(a)

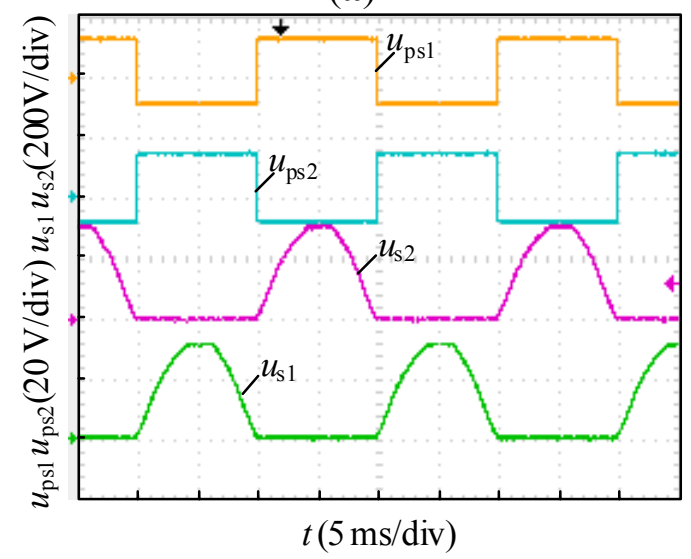

(c)

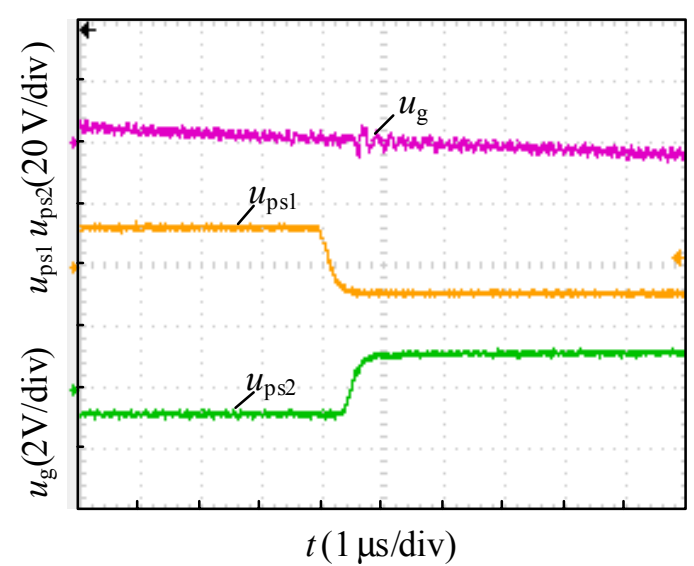

(b)

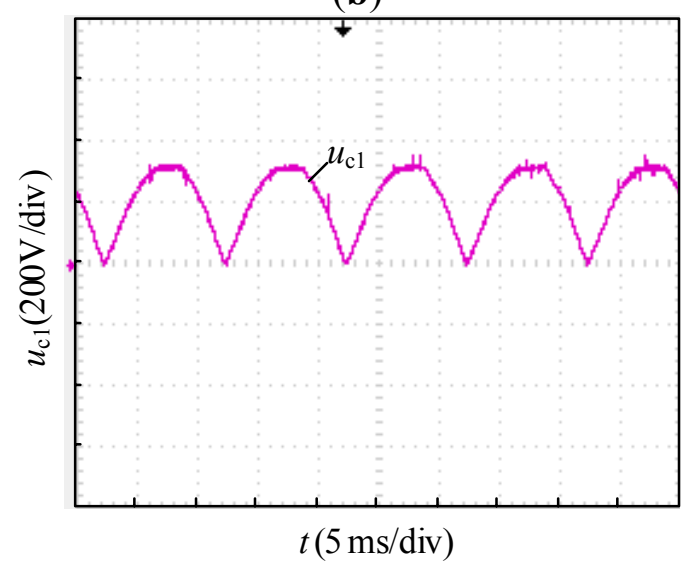

(d)

Figure 25 shows the high-frequency operating waveforms of the BSS-FBC in the discharging mode. In Figure $25 \mathrm{a}, \mathrm{S}_{9}$ and $\mathrm{S}_{10}$ operate alternately according to the operational principles. After $\mathrm{S}_{9}-\mathrm{S}_{12}$ turn off, the voltage stress of $S_{9}$ and $S_{10}$ is $U_{b} / 2$. From Figure $25 b$ it can be seen that if $S_{9}$ and $S_{12}$ (or $S_{10}$ and $S_{11}$ ) are turned on, the inductor current rises linearly, and the voltage stress of the freewheeling diode $\mathrm{S}_{5}$ is zero or $N U_{b}$. When $\mathrm{S}_{9}-\mathrm{S}_{12}$ are turned off, the inductor current declines linearly, and the freewheeling diode $\mathrm{S}_{5}$ turns on. 
Figure 25. High-frequency operating waveforms of BSS-FBC in discharging mode: (a) Driving pulse and voltage stress of $S_{9}, S_{10}$; (b) Voltage stress of $S_{9}$, voltage stress of the freewheeling diode of $\mathrm{S}_{5}$, and inductor current.

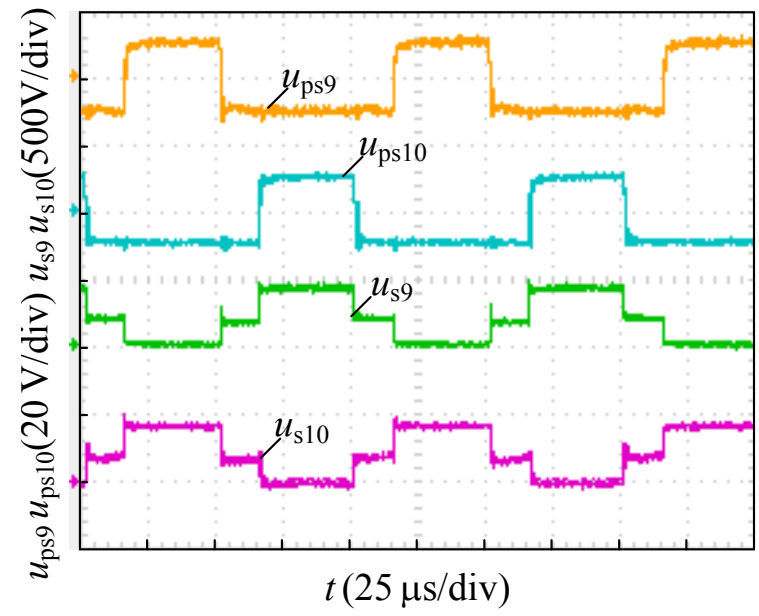

(a)

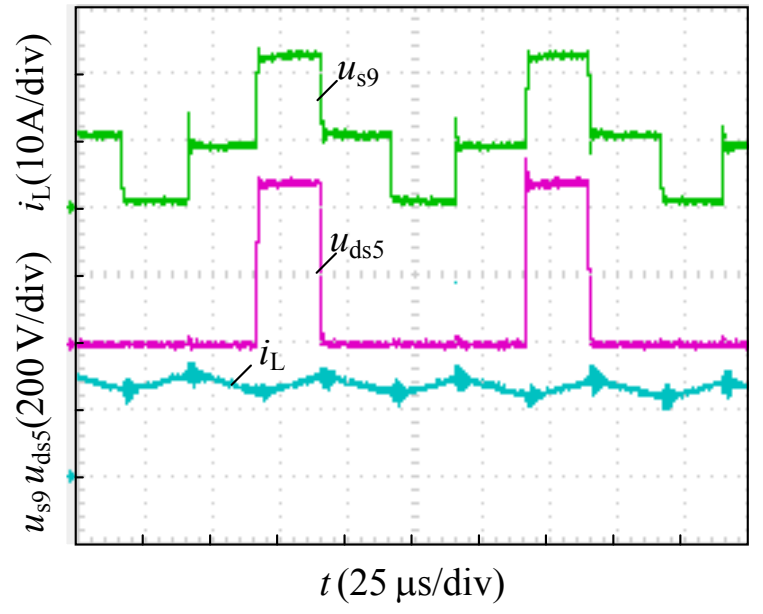

(b)

Figure 26 shows the dynamic response waveforms of the BSS-FBC and typical two-stage topology in a charging or discharging mode. These indicate that the new topology responses rapidly under sudden power changes whose response time is at the level of millisecond and almost has no overshoot. Comparing Figure 26b,e,d,f, it can be seen the response time of BSS-FBC is about 2 ms, shorter than that of typical two-stage topology whose response time is about $4 \mathrm{~ms}$. This excellent dynamic performance validates dynamic characteristics analysis in the previous sections.

Figure 26. Dynamic response waveforms of grid voltage and current of BSS-FBC and typical two-stage topology: (a) Rated power to half power in the charging mode of BSS-FBC; (b) Half power to rated power in the charging mode of BSS-FBC; (c) Rated power to half power in the discharging mode of BSS-FBC; (d) Half power to rated power in the discharging mode of BSS-FBC; (e) Half power to rated power in the charging mode of typical two-stage topology; (f) Half power to rated power in the discharging mode of typical two-stage topology.

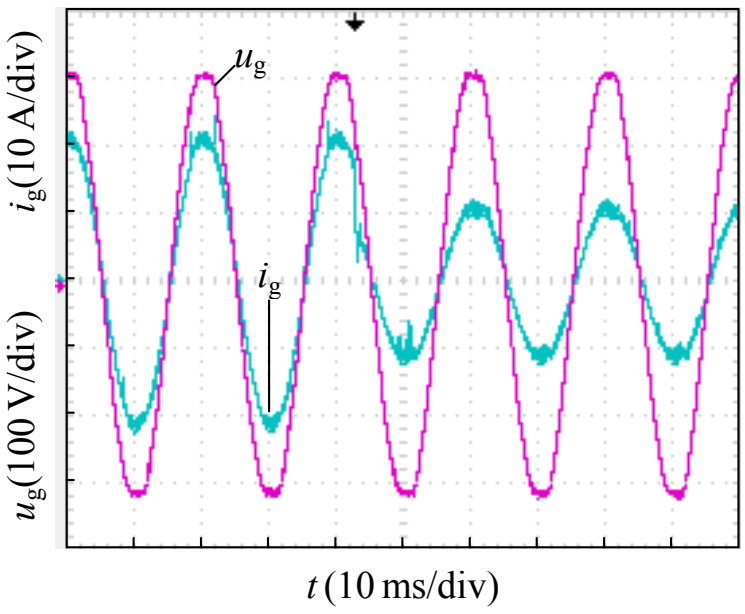

(a)

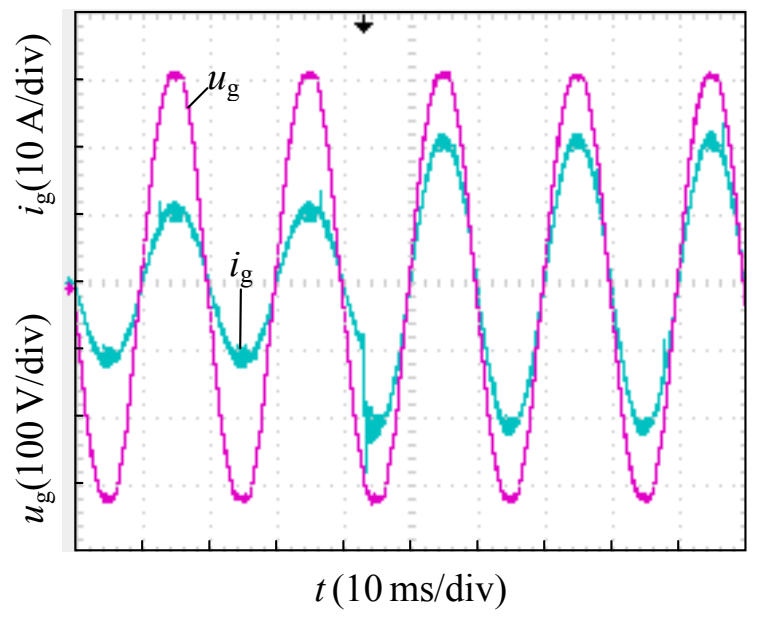

(b) 
Figure 26. Cont.

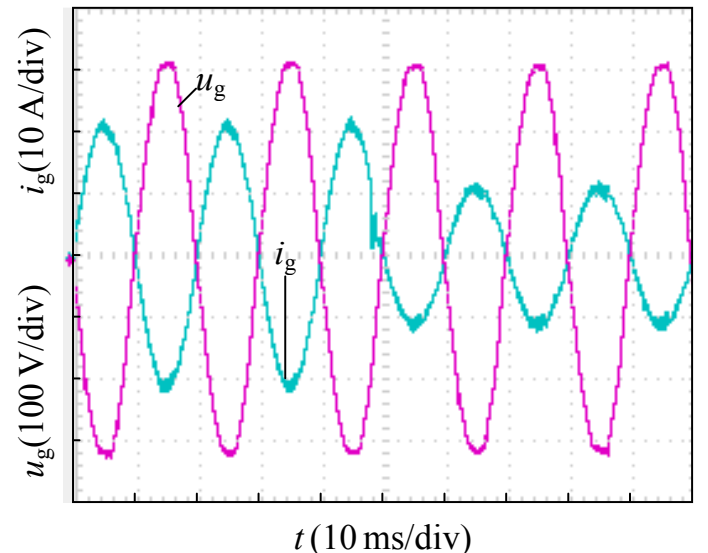

(c)

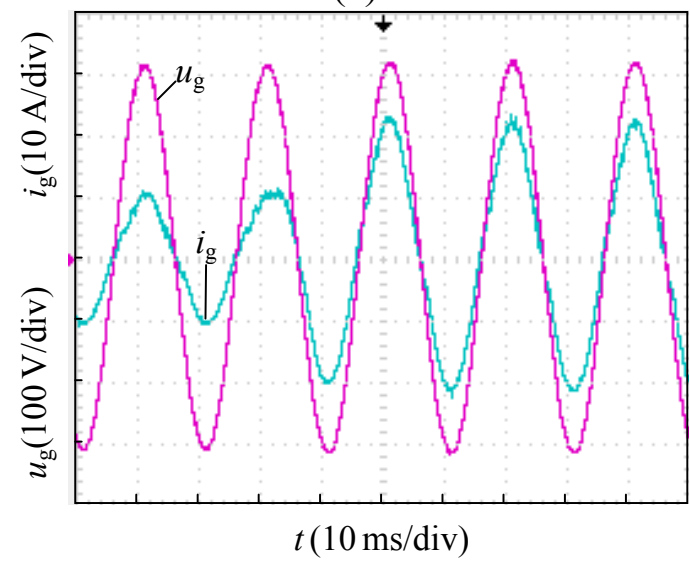

(e)

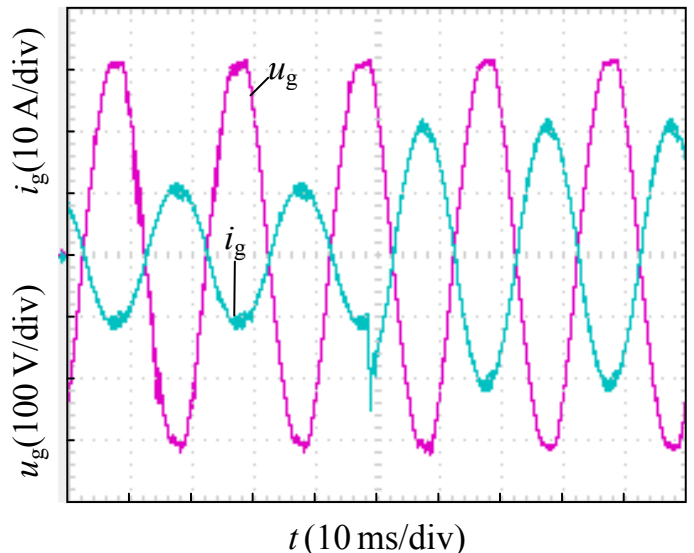

(d)

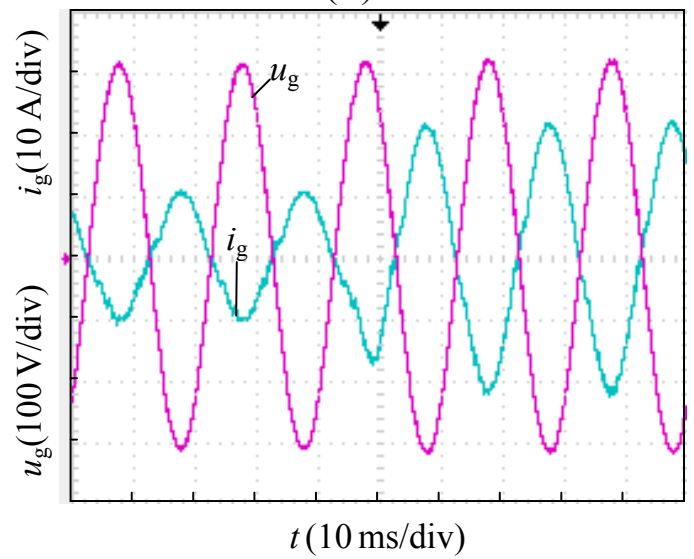

(f)

Figure 27 shows the spectrum analysis of the grid current for BSS-FBC and typical two-stage topology at different percentages of the rated power. The grid current THD of BSS-FBC is $2.8 \%$ at $100 \%$ rated power and $3.5 \%$ at $50 \%$ rated power, which satisfy the related IEEE standards. The grid current THD of typical two-stage topology is $3.4 \%$ at $100 \%$ rated power. Accordingly, power factor of BSS-FBC at $100 \%$ rated power is 0.9996 , achieving the unity power factor operation.

Figure 27. Grid current spectrum analysis of BSS-FBC and typical two-stage topology: (a) $100 \%$ rated power of BSS-FBC; (b) 50\% rated power of BSS-FBC; (c) $100 \%$ rated power of typical two-stage topology.

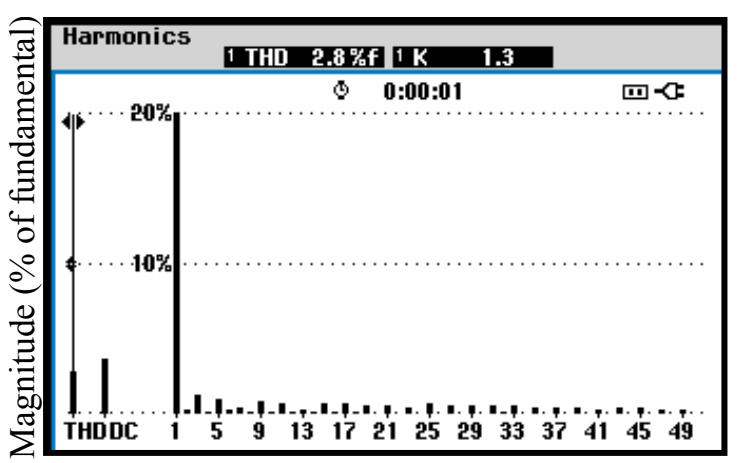

Harmonic order

(a)

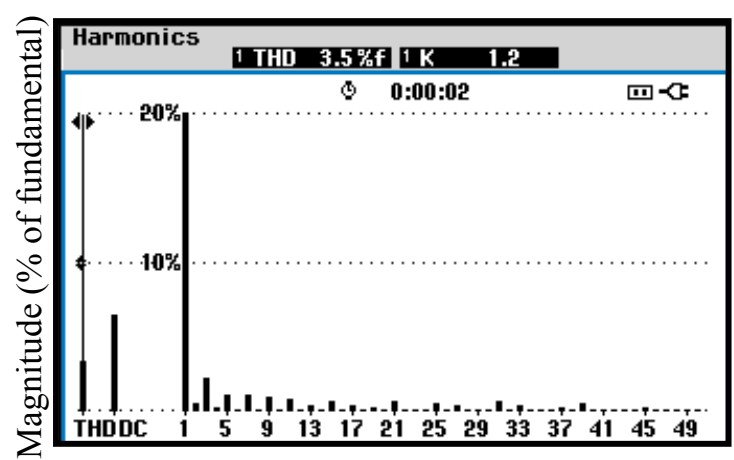

Harmonic order

(b) 
Figure 27. Cont.

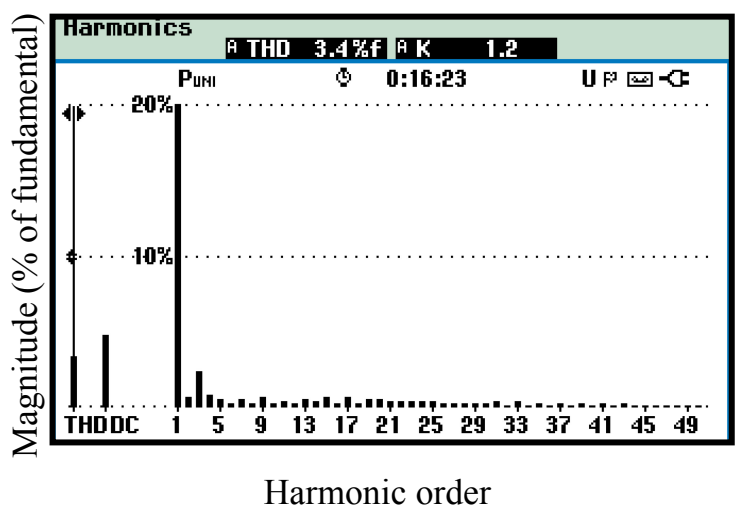

(c)

Table 3 shows the experimental efficiency of the BSS-FBC prototype at full power and other power conditions. The measured results indicate that the efficiencies of the BSS-FBC are mostly above $92 \%$ in different operation modes and power conditions. Those typical topologies discussed in Section 2 are usually composed of the PWM converter primary stage and bidirectional DC/DC secondary stage and the overall efficiency is the product of the two stages and commonly below $90 \%$. For example, the tested peak efficiency of single-phase PWM converter is $97.5 \%$, and the peak efficiency of DAB DC-DC converter is about $92 \%$. Thus, the overall efficiency is $89.7 \%$. It is below $90 \%$. This confirms that the BSS-FBC has a certain advantage in the energy conversion efficiency which makes it suitable for $\mathrm{V} 2 \mathrm{G}$ applications, since energy interaction applications cause the degradation of batteries and V2G is a highly economic conscious field.

Table 3. Measured efficiency of the BSS-FBC prototype $\left(U_{b}=444 \mathrm{~V}\right)$.

\begin{tabular}{ccccc}
\hline Power $\left(\mathbf{\%}_{\boldsymbol{N}}\right)$ & Charging $\boldsymbol{I}_{\boldsymbol{b}}(\mathbf{A})$ & Discharging $\boldsymbol{i}_{\boldsymbol{g}} \boldsymbol{r m s}(\mathbf{A})$ & Charging Efficiency & Discharging Efficiency \\
\hline $100 \%$ & 7.4 & 15 & $92.7 \%$ & $94.2 \%$ \\
$75 \%$ & 5.6 & 11.3 & $94.6 \%$ & $95.7 \%$ \\
$50 \%$ & 3.7 & 7.5 & $94.9 \%$ & $95.4 \%$ \\
$30 \%$ & 2.2 & 4.5 & $91.8 \%$ & $92.4 \%$ \\
\hline
\end{tabular}

\section{Conclusions}

This paper introduces a novel high power factor bidirectional single-stage full-bridge topology (BSS-FBC) suitable for V2G applications. Compared with other typical topologies, in addition to achieving similar high frequency isolation and bidirectional energy conversion, it offers several highly desirable features such as high power density, small size, light weight, low cost, high efficiency, high power factor, small harmonic pollution, good dynamic performance, simple control, high reliability, and low complexity. Its operational principles and control strategies in the charging and discharging modes are presented. Since the harmonic index is of critical importance to the interface with the utility grid, harmonic analysis on the basis of double-Fourier integral is performed with comparison of line current harmonic characteristic between the BSS-FBC topology and existing unipolar/bipolar controlled single-phase PWM converters. For energy interaction, excellent dynamic characteristic is necessary. This paper establishes dynamic modes for the BSS-FBC, analyzes its dynamic 
characteristic, compares to single-phase PWM converters that act as the first stage of typical two-stage topologies. The design considerations for the key parameters of this topology are presented. Furthermore, the main advantages and unique features of this novel topology are comprehensively discussed and verified. Finally, a $3.3 \mathrm{~kW}$ prototype of the proposed BSS-FBC technology is developed, and its excellent characteristics are verified by experiment in a vehicle application.

There are some open issues in the directions described in this paper. At present, the new topology cannot manipulate the phase angle of the current which is a useful feature for power factor control. Adding this feature will be a valuable research topic. Continuous improvement of power conversion efficiency via theoretical calculation, topology improvement, component selections, and control technology will be essential for interaction applications in V2G. In addition, miniaturization design of the converter is another important topic for broad application of this technology.

\section{Acknowledgments}

This research was supported in part by International S\&T Cooperation Program of China under grant S2013GR0346; and in part by the National High Technology Research and Development of China (863 Program) under grant 2011AA05A108.

\section{Author Contributions}

Jiuchun Jiang and Yan Bao proposed the novel topology and its control strategy, also the harmonic analysis. Yan Bao completed the experiments. Le Yi Wang contributed to the dynamic model and its compensator design, also modified this paper written by Jiang and Bao.

\section{Conflicts of Interest}

The authors declare no conflict of interest.

\section{References}

1. Amin, S.M.; Wollenberg, B.F. Toward a smart grid: Power delivery for the 21 st century. IEEE Power Energy Mag. 2005, 3, 34-41.

2. Ipakchi, A.; Albuyeh, F. Grid of the future. IEEE Power Energy Mag. 2009, 7, 52-62.

3. Chan, C.C. The state of the art of electric and hybrid vehicles. Proc. IEEE 2002, 90, 247-275.

4. Chan, C.C. The state of the art of electric, hybrid, and fuel cell vehicles. Proc. IEEE 2007, 95, 704-718.

5. Clement-Nyns, K.; Haesen, E.; Driesen, J. The impact of charging plug-in hybrid electric vehicles on a residential distribution grid. IEEE Trans. Power Syst. 2010, 25, 371-380.

6. Lopes, J.A.P.; Soares, F.J.; Almeida, P.M.R. Integration of electric vehicles in the electric power system. Proc. IEEE 2011, 99, 168-183.

7. Kempton, W.; Letendre, S.E. Electric vehicles as a new power source for electric utilities. Transp. Res. Part D 1997, 2, 157-175.

8. Kempton, W.; Tomić, J. Vehicle-to-grid power fundamentals: Calculating capacity and net revenue. J. Power Sources 2005, 144, 268-279. 
9. Kempton, W.; Tomić, J. Vehicle-to-grid power implementation: From stabilizing the grid to supporting large-scale renewable energy. J. Power Sources 2005, 144, 280-294.

10. Tomić, J.; Kempton, W. Using fleets of electric-drive vehicles for grid support. J. Power Sources 2007, 168, 459-468.

11. Clement-Nyns, K.; Haesen, E.; Driesen, J. The impact of vehicle-to-grid on the distribution grid. Electric Power Syst. Res. 2011, 81, 185-192.

12. Yu, Y.F.; Zhang, Q.F.; Liang, B.; Liu, X.F.; Cui, S.M. Analysis of a single-phase Z-source inverter for battery discharging in vehicle to grid applications. Energies 2011, 4, 2224-2235.

13. Jian, L.N.; Xue, H.H.; Xu, G.Q.; Zhu, X.Y.; Zhao, D.F.; Shao, Z.Y. Regulated charging of plug-in hybrid electric vehicles for minimizing load variance in household smart microgrid. IEEE Trans. Ind. Electron. 2013, 60, 3218-3226.

14. Luo, Z.W.; Hu, Z.C.; Song, Y.H.; Xu, Z.W.; Lu, H.Y. Optimal coordination of plug-in electric vehicles in power grids with cost-benefit analysis-Part I: Enabling techniques. IEEE Trans. Power Syst. 2013, 28, 3546-3555.

15. Luo, Z.W.; Hu, Z.C.; Song, Y.H.; Xu, Z.W.; Lu, H.Y. Optimal coordination of plug-in electric vehicles in power grids with cost-benefit analysis-Part II: A case study in China. IEEE Trans. Power Syst. 2013, 28, 3556-3565.

16. Wang, Z.P.; Wang, S. Grid power peak shaving and valley filling using vehicle-to-grid systems. IEEE Trans. Power Deliver. 2013, 28, 1822-1829.

17. Soares, J.; Morais, H.; Sousa, T.; Vale, Z.; Faria, P. Day-ahead resource scheduling including demand response for electric vehicles. IEEE Trans. Smart Grid 2013, 4, 596-605.

18. Yao, W.F.; Zhao, J.H.; Wen, F.S.; Xue, Y.S.; Ledwich, G. A hierarchical decomposition approach for coordinated dispatch of plug-in electric vehicles. IEEE Trans. Power Syst. 2013, 28, $2678-2778$.

19. Mu, Y.F.; Wu, J.Z.; Ekanayake, J.; Jenkins, N.; Jia, H.J. Primary frequency response from electric vehicles in the great britain power system. IEEE Trans. Smart Grid 2013, 4, 1142-1150.

20. Geng, B.; Mills, J.K.; Sun, D. Two-stage charging strategy for plug-in electric vehicles at the residential transformer level. IEEE Trans. Smart Grid 2013, 4, 1442-1452.

21. Hu, W.H.; Su, C.; Chen, Z.; Bak-Jensen, B. Optimal operation of plug-in electric vehicles in power systems with high wind power penetrations. IEEE Trans. Sustain. Energy 2013, 4, 577-585.

22. Singh, M.; Kumar, P.; Kar, I. A multi charging station for electric vehicles and its utilization for load management and the grid support. IEEE Trans. Smart Grid 2013, 4, 1026-1037.

23. Mohamed, A.; Salehi, V.; Ma, T.; Mohamed, O.A. Real-time energy management algorithm for plug-in hybrid electric vehicle charging parks involving sustainable energy. IEEE Trans. Sustain. Energy 2014, 5, 577-586.

24. Singh, M.; Thirugnanam, K.; Kumar, P.; Kar, I. Real-time coordination of electric vehicles to support the grid at the distribution substation level. IEEE Syst. J. 2013, PP, 1-11.

25. Chukwu, U.C.; Mahajan, S.M. Real-time management of power systems with V2G facility for smart-grid applications. IEEE Trans. Sustain. Energy 2014, 5, 558-566.

26. Sun, S.; Dong, M.; Liang, B. Real-time welfare-maximizing regulation allocation in dynamic aggregator-EVs system. IEEE Trans. Smart Grid 2014, 5, 1397-1409. 
27. Kennel, F.; Gorges, D.; Liu, S. Energy management for smart grids with electric vehicles based on hierarchical MPC. IEEE Trans. Ind. Inf. 2013, 9, 1528-1537.

28. Gao, S.; Chau, K.T.; Liu, C.H.; Wu, D.Y.; Chan, C.C. Integrated energy management of plug-in electric vehicles in power grid with renewables. IEEE Trans. Veh. Technol. 2014, PP, 1-8.

29. Liu, H.; Hu, Z.C.; Song, Y.H.; Lin, J. Decentralized vehicle-to-grid control for primary frequency regulation considering charging demands. IEEE Trans. Power Syst. 2013, 28, 3480-3489.

30. Vachirasricirikul, S.; Ngamroo, I. Robust LFC in a smart grid with wind power penetration by coordinated V2G control and frequency controller. IEEE Trans. Smart Grid 2014, 5, 371-380.

31. Thirugnanam, K.; Joy, T.P.; Singh, M.; Kumar, P. Mathematical modeling of Li-Ion battery using genetic algorithm approach for V2G applications. IEEE Trans. on Energy Conver. 2014, 29, 332-343.

32. Landi, M.; Gross, G. Measurement techniques for online battery state of health estimation in vehicle-to-grid applications. IEEE Trans. Instrum. Meas. 2014, 63, 1224-1234.

33. Ustun, T.S.; Ozansoy, C.R.; Zayegh, A. Implementing vehicle-to-grid (V2G) technology with IEC 61850-7-420. IEEE Trans. Smart Grid 2013, 4, 1180-1187.

34. Xu, D.Q.; Joós, G.; Lévesque, M.; Maier, M. Integrated V2G, G2V, and renewable energy sources coordination over a converged fiber-wireless broadband access network. IEEE Trans. Smart Grid 2013, 4, 1381-1390.

35. Liu, H.; Ning, H.S.; Zhang, Y.; Xiong, Q.X.; Yang, L.T. Role-dependent privacy preservation for secure V2G networks in the smart grid. IEEE Trans. Inf. Forens. Secur. 2014, 9, 208-220.

36. NIST Framework and Roadmap for Smart Grid Interoperability Standards; National Institute of Standards and Technology: Gaithersburg, MD, USA, 2010.

37. Yilmaz, M.; Krein, P.T. Review of battery charger topologies, charging power levels, and infrastructure for plug-in electric and hybrid vehicles. IEEE Trans. Power Electron. 2013, 28, 2151-2169.

38. Inoue, S.; Akagi, H. A bidirectional DC/DC converter for an energy storage system with galvanic isolation. IEEE Trans. Power Electron. 2007, 22, 2299-2306.

39. Khaligh, A.; Dusmez, S. Comprehensive topological analysis of conductive and inductive charging solutions for plug-in electric vehicles. IEEE Trans. Veh. Technol. 2012, 61, 3475-3489.

40. Haghbin, S.; Lundmark, S.; Alaküla, M.; Carlson, O. Grid-connected integrated battery chargers in vehicle applications: Review and new solution. IEEE Trans. Ind. Electron. 2013, 60, 459-473.

41. Haghbin, S.; Khan, K.; Lundmark, S.; Alaküla, M.; Carlson, O.; Leksell, M.; Wallmark, O. Integrated chargers for EV's and PHEV's: Examples and new solutions. In Proceedings of the 2010 XIX International Conference on Electrical Machines, Rome, Italy, 6-8 September 2010; pp. 1-6.

42. Bruyère, A.; Sousa, L.D.; Bouchez, B.; Sandulescu, P.; Kestelyn, X.; Semail, E. A multiphase traction/fast-battery-charger drive for electric or plug-in hybrid vehicles: Solutions for control in traction mode. In Proceedings of the 2010 IEEE Vehicle Power and Propulsion Conference (VPPC), Lille, France, 1-3 September 2010; pp. 1-7.

43. Lacroix, S.; Laboure, E.; Hilairet, M. An integrated fast battery charger for electric vehicle. In Proceedings of the 2010 IEEE Vehicle Power and Propulsion Conference (VPPC), Lille, France, 1-3 September 2010; pp. 1-6. 
44. Sousa, L.D.; Silvestre, B.; Bouchez, B. A combined multiphase electric drive and fast battery charger for electric vehicles. In Proceedings of the 2010 IEEE Vehicle Power and Propulsion Conference (VPPC), Lille, France, 1-3 September 2010; pp. 1-6.

45. Haghbin, S.; Alaküla, M.; Khan, K.; Lundmark, S.; Leksell, M.; Wallmark, O.; Carlson, O. An integrated charger for plug-in hybrid electric vehicles based on a special interior permanent magnet motor. In Proceedings of the 2010 IEEE Vehicle Power and Propulsion Conference (VPPC), Lille, France, 1-3 September 2010; pp. 1-6.

46. Rodrigues, M.C.B.P.; Souza, I.; Ferreira, A.A.; Barbosa, P.G.; Braga, H.A.C. Integrated bidirectional single-phase vehicle-to-grid interface with active power filter capability. In Proceedings of 2013 Brazilian Power Electronics Conference (COBEP), Gramado, Brazil, 27-31 October 2013; pp. 993-1000.

47. Khan, M.A.; Husain, I.; Sozer, Y. Integrated electric motor drive and power electronics for bidirectional power flow between the electric vehicle and DC or AC grid. IEEE Trans. Power Electron. 2013, 28, 5774-5783.

48. Haghbin, S.; Khan, K.; Shuang Z.; Alakula, M.; Lundmark, S.; Carlson, O. An integrated 20-kW motor drive and isolated battery charger for plug-in vehicles. IEEE Trans. Power Electron. 2013, $28,4013-4029$.

49. IEEE Standard for Interconnecting Distributed Resources with Electric Power Systems; The Institute of Electrical and Electronics Engineers: New York, NY, USA, 2003.

50. Electromagnetic Compatibility (EMC)—Part 3-2: Limits—Limits for Harmonic Current Emissions (Equipment Input Current $\leq 16$ A per Phase); International Electrotechnical Commission: Geneva, Switzerland, 2000.

51. Jarnut, M.; Benysek, G. Application of power electronics devices in smart grid and V2G (vehicle to grid) technologies. Prz. Elektrotech. 2010, 86, 93-96.

52. Kisacikoglu, M.C.; Ozpineci, B.; Tolbert, L.M. Effects of V2G reactive power compensation on the component selection in an EV or PHEV bidirectional charger. In Proceedings of the IEEE Energy Conversion Congress and Exposition (ECCE), Atlanta, GA, USA, 12-16 September 2010; pp. 870-876.

53. Pinto, J.G.; Monteiro, V.; Gonçalves, H.; Afonso, J.L. Onboard reconfigurable battery charger for electric vehicles with traction-to-auxiliary mode. IEEE Trans. Veh. Technol. 2014, 63, 1104-1116.

54. Pinto, J.G.; Monteiro, V.; Goncalves, H.; Exposto, B.; Pedrosa, D.; Couto, C.; Afonso, J.L. Bidirectional battery charger with Grid-to-Vehicle, Vehicle-to-Grid and Vehicle-to-Home technologies. In Proceedings of the 39th Annual Conference of the IEEE Industrial Electronics Society, IECON 2013, Vienna, Austria, 10-13 November 2013; pp. 5934-5939.

55. Khan, M.A.; Husain, I.; Sozer, Y. A bi-directional DC-DC converter with overlapping input and output voltage ranges and vehicle to grid energy transfer capability. In Proceedings of 2012 IEEE International Electric Vehicle Conference (IEVC), Greenville, CA, USA, 4-8 March 2012; pp. 1-7.

56. Hegazy, O.; Barrero, R.; Mierlo, J.V.; Lataire, P.; Omar, N.; Coosemans, T. An advanced power electronics interface for electric vehicles applications. IEEE Trans. Power Electron. 2013, 28, 5508-5521. 
57. Wong, N.; Kazerani, M. A review of bidirectional on-board chargertopologies for plugin vehicles. In Proceedings of the 25th IEEE Canadian Conference on Electrical \& Computer Engineering (CCECE), Montreal, Canada, 29 April-2 May 2012; pp. 1-6.

58. De Doncker, R.W.A.A.; Divan, D.M.; Kheraluwala, M.H. A three-phase soft-switched high-power-density DC/DC converter for high-power applications. IEEE Trans. Ind. Appl. 1991, $27,63-73$.

59. Xie, Y.H.; Sun, J.; Freudenberg, J.S. Power flow characterization of a bidirectional galvanically isolated high-power DC/DC converter over a wide operating range. IEEE Trans. Power Electron. 2010, 25, 54-66.

60. Shi, X.L.; Jiang, J.C.; Guo, X.T. An efficiency-optimized isolated bidirectional DC-DC converter with extended power range for energy storage systems in microgrids. Energies 2013, 6, 27-44.

61. Kanaan, H.Y.; Caron, M.; Al-Haddad, K. Design and implementation of a two-stage grid-connected high efficiency power load emulator. IEEE Trans. Power Electron. 2014, 29, 3997-4006.

62. Zhao, B.; Song, Q.; Liu, W.H.; Sun, Y.D. Overview of dual-active bridge isolated bidirectional dc-dc converter for high frequency-link power-conversion system. IEEE Trans. Power Electron. 2014, 29, 4091-4106.

63. Pan, X.; Rathore, A.K. Novel bidirectional snubberless naturally commutated soft-switching current-fed full-bridge isolated DC/DC converter for fuel cell vehicles. IEEE Trans. Ind. Electron. 2014, 61, 2307-2315.

64. Li, X.D.; Bhat, A.K.S. Analysis and design of high-frequency isolated dual-bridge series resonant DC/DC converter. IEEE Trans. Power Electron. 2010, 25, 850-862.

65. Ebrahimi, S.; Taghavi, M.; Tahami, F.; Oraee, H. Integrated bidirectional isolated soft-switched battery charger for vehicle-to-grid technology using4-Switch 3థ-rectifier. In Proceedings of the 39th Annual Conference of the IEEE Industrial Electronics Society, IECON 2013, Vienna, Austria, 10-13 November 2013; pp. 906-911.

66. Madawala, U.K.; Thrimawithana, D.J. A bidirectional inductive power interface for electric vehicles in V2G systems. IEEE Trans. Ind. Electron. 2011, 58, 4789-4796.

67. Thrimawithana, D.J.; Madawala, U.K. A novel matrix converter based bi-directional IPT power interface for V2G applications. In Proceedings of the IEEE International Energy Conference and Exhibition (EnergyCon), Manama, Bahrain, 18-22 December 2010; pp. 495-500.

68. Weise, N.D.; Gastelino, G.; Basu, K.; Mohan, N. A single-stage dual-active-bridge-based soft switched AC-DC converter with open-loop power. IEEE Trans. Power Electron. 2014, 29 , 4007-4016.

69. Reimensnyder, N.; Weise, N. Voltage control of a single phase, single-stage, isolated AC-DC converter. In Proceedings of the IEEE Transportation Electrification Conference and Expo (ITEC), Detroit, MI, USA, 16-19 June 2013; pp. 1-5.

70. Varajao, D.; Araujo, R.E.; Moreira, C.; Lopes, J.P. Impact of phase-shift modulation on the performance of a single-stage bidirectional electric vehicle charger. In Proceedings of the 38th Annual Conference on IEEE Industrial Electronics Society, Montreal, QC, Canada, 25-28 October 2012; pp. 5215-5220.

71. Sanjaya, M. Switching Power Supply Design and Optimization; McGraw-Hill: New York, NY, USA, 2005; pp. 92-95. 
72. IEEE Recommended Practices and Requirements for Harmonic Control in Electrical Power Systems; The Institute of Electrical and Electronics Engineers: New York, NY, USA, 1993.

73. Holmes, D.G.; Lipo, T.A. Pulse Width Modulation for Power Converters: Principles and Practice; IEEE Press: Piscataway, NJ, USA, 2003; pp. 155-211.

74. Sekyung, H.; Soohee, H.; Sezaki, K. Development of an optimal vehicle-to-grid aggregator for frequency regulation. IEEE Trans. Smart Grid 2010, 1, 65-72.

75. Huliehel, F.A.; Lee, F.C.; Cho, B.H. Small-signal modeling of the single-phase boost high power factor converter with constant frequency control. In Proceedings of the 23rd Annual IEEE Power Electronics Specialists Conference, Toledo, OH, USA, 29 June-3 July 1992; pp. 475-482.

76. Xie, M.J.; Lu, B.; Dong, W.; Lee, F.C. Novel current-loop feed-forward compensation for boost PFC converter. In Proceedings of the IEEE 19th Annual IEEE Applied Power Electronics Conference and Exposition, Anaheim, CA, USA, 22-26 February 2004; pp. 750-775.

77. Hang, L.J.; Yao, W.X.; Lu, Z.Y.; Qian, Z.M.; Guerrero, J.M. Analysis of flux density bias and digital suppression strategy for single-stage power factor corrector converter. IEEE Trans. Ind. Electron. 2008, 55, 3077-3087.

(C) 2014 by the authors; licensee MDPI, Basel, Switzerland. This article is an open access article distributed under the terms and conditions of the Creative Commons Attribution license (http://creativecommons.org/licenses/by/3.0/). 